
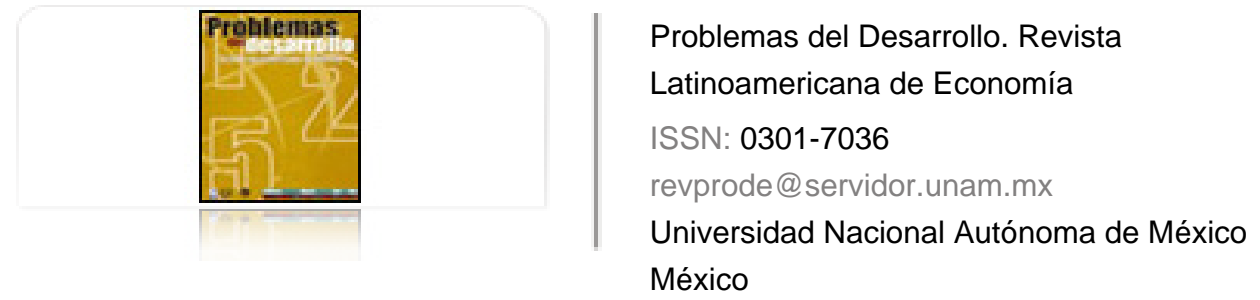

Lindenboim, Javier

Distribución funcional del ingreso, un tema olvidado que reclama atención Problemas del Desarrollo. Revista Latinoamericana de Economía, vol. 39, núm. 153, abril-junio, 2008, pp. 83-117

Universidad Nacional Autónoma de México

Distrito Federal, México

Disponible en: http://www.redalyc.org/articulo.oa?id=11820161004

Cómo citar el artículo

Número completo

- Más información del artículo

Página de la revista en redalyc.org

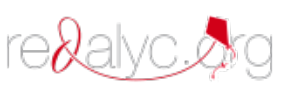

Sistema de Información Científica

Red de Revistas Científicas de América Latina, el Caribe, España y Portugal Proyecto académico sin fines de lucro, desarrollado bajo la iniciativa de acceso abierto 


\title{
DISTRIBUCIÓN FUNCIONAL DEL INGRESO, UN TEMA OLVIDADO QUE RECLAMA ATENCIÓN
}

\author{
Javier Lindenboim*
}

Fecha de recepción: 9 de noviembre de 2007. Fecha de aceptación: 21 de abril de 2008.

\section{Resumen}

Las discusiones conceptuales en América Latina acerca del comportamiento socioeconómico de la región y de las evidencias sobre los rasgos dominantes de inequidad se han focalizado en las últimas décadas en torno de las medidas de dispersión o de concentración del ingreso percibido por las personas o las familias. Sin embargo, no han incluido, por lo general, el referido a la manera en que los factores productivos logran apropiarse de la riqueza que anualmente se genera en cada uno de nuestros países. El propósito básico de este artículo es llamar la atención en tal sentido. Para tal fin, se menciona la escasa producción académica al respecto en nuestra región al tiempo que se alude a la no muy abundante información disponible. Todo ello se ilustra con el caso de Argentina.

Palabras clave: mercado de trabajo, distribucion funcional del ingreso, América Latina, Argentina, productividad y salarios.

* Investigador principal del Consejo Nacional de Investigaciones Científicas y Técnicas (CONICET) y director del Centro de Estudios sobre Población, Empleo y Desarrollo (CEPED) de la Universidad de Buenos Aires. Correo electrónico: lindenboim.uba@ gmail.com.

Agradezco a los miembros del CEPED, Carla Borroni, Juan M. Graña, Alejandro M. Lavopa y Jimena Valdez, por la atenta lectura de una versión preliminar, así como por la ayuda en el reprocesamiento de parte de la información incluida. Obviamente, carecen de responsabilidad por los errores que pudieran subsistir. 


\section{Summary}

The conceptual debates in Latin America about the region's socio-economic performance and the evidence for its dominant features of inequity in the last few decades have focused on the measures of dispersion or concentration of the income received by individuals or families. Unfortunately, they have not generally included any reference to the way the productive factors manage to appropriate the wealth that is annually generated in each of our countries. The basic proposal of this study is, precisely, to call attention to this aspect. With this in mind, it notes the limited academic production on this in our region, while at the same time alluding to the not very abundant available information. All of this is illustrated for the case of Argentina.

Key words: labor market, functional income distribution, Latin America, Argentina, productivity; wages.

\section{Résumé}

Les discussions conceptuelles en Amérique latine sur le comportement socio-économique de la région et les indices évidents d'une prévalence de l'iniquité se sont centrées, au long des dernières décennies, sur les mesures de dispersion ou de concentration du revenu perçu par les personnes ou les familles. Malheureusement, elles ne se sont pas référées, en général, à la manière dont les facteurs productifs arrivent à s'approprier la richesse annuellement générée dans chacun de nos pays. Le but initial de cet article est justement d'éveiller l'attention sur ce point. Pour autant, il est fait mention de la rare production académique sur ce thème dans notre région de même que de la peu abondante information disponible. Tout cela est illustré par le cas de l'Argentine.

Mots clés: marché du travail, distribution fonctionnelle du revenu, Amérique latine, Argentine, productivité et salaires.

\section{Resumo}

AsdiscussõesconceptuaisnaAméricaLatinaemtornodocomportamentosocioeconômico da região e das evidências sobre os traços dominantes de iniqüidade se focalizaram nas últimas décadas em torno das medidas de dispersão ou de concentração do ingresso recebido pelas pessoas ou pelas famílias. Infelizmente, não incluíram, geralmente, o que se refere à maneira em que os fatores produtivos conseguem se apropriar da riqueza que anualmente se gera en cada um dos nossos países. O propósito básico deste artigo é, precisamente, chamar a atenção nesse sentido. Para tal finalidade, menciona-se a escassa produção acadêmica ao respeito em nossa região ao mesmo tempo em que se faz alusão à não muito abundante informação disponível. Tudo isso se ilustra com o caso da Argentina.

Palavras-chave: mercado de trabalho, distribuiçao funcional do ingresso, América Latina, Argentina, produtividade e salários. 


\section{La coyuntura impresiona pero no suele explicar}

P

arece que tenemos en la región una gran predisposición a hablar de los problemas que más nos aquejan, adjudicándoselos a lo más inmediato que nos tocó vivir. Quizás el caso de Argentina sirva como ilustración. Cuando estábamos en medio del drama de 2002, luego del estallido del régimen de convertibilidad, ${ }^{1}$ la cuestión podía resumirse en señalar como responsable al entonces ministro de Economía, Domingo Cavallo, o al gobierno de la Alianza que precedió a ese verano tan particular. En el medio de ese gobierno de la Alianza todos los males parecían haberse iniciado en el decenio durante el cual el presidente de la nación fue Carlos Menem (1989-1999); cuando estábamos transcurriendo ese lapso, para muchos el origen estaba en la hiperinflación producida durante el final del gobierno de la Unión Cívica Radical; ni hablar de que, al retornar la democracia (1983), se asignaba la

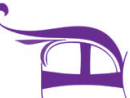
causa de los problemas económicos que transitábamos — que, mirados desde hoy, parecen nimios - a la política aplicada durante la dictadura militar. Quienes tienen mayor memoria pueden seguir agregando elementos que en cada instancia se fueron focalizando como las reales o presuntas razones de las circunstancias que en distintos momentos expresaban los conflictos y tensiones por las insatisfacciones. El lector de cada país podrá hacer asociaciones aplicables a su respectivo contexto.

Justamente en una simplificación extrema de tal tipo —que tenemos incorporada con mucha naturalidad, hacia lo acontecido inmediatamente antes- radicaría uno de los inconvenientes más perniciosos. Al considerar las cosas en esos términos, dejamos de pensar en cuáles son las razones que estructuran nuestros conflictos. Por eso el planteo de discernir entre lo que vemos que acontece y una mirada más estructural, de largo plazo, es una propuesta que no debería dejar de acompañarnos.

La otra cuestión, asociada a la anterior, es la que surge de la siguiente interrogante: ¿para qué mirar el largo plazo, si es casi inasible? Sólo le debería interesar a quien lo analiza como parte de su ejercicio profesional o académico, pero fuera de eso no le asignamos valor o significación. Un agregado adicional —negativo, según el punto de vista aquí sostenido - es que todo esto tiende a estar atado a una mirada tan desafortunada como la anterior, cuyos ejemplos habremos escuchado más asiduamente de lo que merecen por parte de los tomadores de decisión. "No se trata de hacer diagnósticos porque sí, porque ya hay muchos que se hicieron; tenemos que saber qué hacer". Sin

1 Con ese nombre se hizo conocido el esquema consistente en el restablecimiento de una caja de conversión (que había desparecido en Argentina con la crisis de 1930) operado en 1991. 
embargo, debemos preguntarnos: ¿es posible saber qué hacer sin un diagnóstico?, o ¿qué podemos hacer si creemos que el diagnóstico que existe no está suficientemente fundado, ni es del todo profundo o definitorio? Probablemente esta subestimación de la labor diagnóstica no nos ayude a encontrar la naturaleza sustantitva de nuestros problemas y, por ende, de los eventuales caminos por recorrer.

Es debido, precisamente, a la preocupación por no quedar en las evidencias más visibles que se rescata aquí la inquietud por la distribución funcional (o apropiación factorial) del ingreso. Simplificando quizás en demasía, podemos convenir que los ingresos de los hogares (cuyas disparidades a menudo son objeto de meticulosos análisis según su estratificación) no son obtenidos por obra del azar o de circunstancias más o menos fortuitas. Esencialmente están determinadas por la posición que los miembros del hogar tienen en el proceso productivo: ese ingreso puede derivar del desempeño de tareas asalariadas, de la propiedad de unidades productivas, del trabajo autónomo o por cuenta propia.

Las facetas múltiples del circuito productivo incluyen no sólo la instancia de generación de bienes y servicios finales (habitualmente estimada en virtud de la cuantificación del aporte hecho por cada una de las ramas de actividad, según las clasificaciones existentes o disponibles), sino también la de la utilización de los mismos en sus papeles principales asociados con la naturaleza diferencial de los diversos componentes de la demanda (consumo privado o de los hogares; consumo público; inversión; exportaciones netas). Pero, al mismo tiempo, se predetermina la apropiación que pueden realizar los partícipes en dicho proceso. El producto o valor agregado, dicen las cuentas nacionales, no es otra cosa que el nuevo valor que incorpora el ciclo productivo por sobre el preexistente (expresado en los insumos utilizados). Y ese nuevo valor se descompone en la retribución factorial, es decir, en salarios y excedente de explotación.

Las diversas concepciones teóricas explican de distinto modo ese reparto. Algunas aluden a la existencia de una determinación de la cuantía del salario vía la productividad del trabajo. Otras, en cambio, sostienen que tal retribución cubre apenas una porción del valor que ese mismo trabajo ejercido logró plasmar. Pero aun dejando pendiente de dilucidación dichos mecanismos, no parece haber posibilidad de dudas acerca de que es en ese proceso productivo cuando se determina el monto a repartir y, por supuesto, cómo hacerlo.

Luego de ello podrán existir mecanismos variados con los cuales la sociedad puede "interferir" en tal reparto. Sin duda, uno de los más importantes es el ejercido por la acción estatal que puede imponer cargas fiscales para proporcionar bienes o servicios (o, incluso, erogaciones en moneda contante y sonante), de modo tal que 
puedan morigerarse las desigualdades surgidas del proceso económico vigente. De manera que el reparto inicial (o distribución primaria) es seguido —o, al menos, es posible que sea seguido— - por otro cuya denominación apropiada es de redistribución (o distribución secundaria).

El resultado de ambos procesos o mecanismos termina expresado en la magnitud de los ingresos disponibles para las personas o las familias. Por tanto, la consideración de la cuantía diferencial de esos ingresos nos informa cabalmente de la inequitativa disponibilidad de los ingresos, pero no de la fuente específica de la misma.

Precisamente este complejo proceso no es el que suele estar en condiciones de ser capturado cuando se pone el acento principal en la indagación de las circunstancias inmediatas, en vez de las de orden estructural o de largo plazo. Por tanto, se intenta prestar atención a estas últimas en el presente texto. El primer paso será observar qué información está disponible para la región.

\section{La participación salarial en América Latina y el mundo}

Un aspecto de gran significación está asociado con la información y con los análisis en los países de la región. $\mathrm{O}$, más bien, sobre la escasez de la primera y lo limitado de los otros. El propio cambio de la denominación de distribución funcional o apropiación factorial por la actual indudablemente más "neutra" Cuenta Generación de Ingresos sugiere una situación, al menos, llamativa. En ese marco de escasez informativa, aquí se tomará parte de la recopilación realizada por Graña (2006), en su carácter de becario dirigido por el autor.

En ese documento se han reunido series de diferentes países y distintos niveles de desarrollo. Obviamente hay que destacar que las series no son necesariamente comparables; el único criterio adoptado para realizar esta comparación ha sido que se obtengan de Sistemas de Cuentas Nacionales y con las mismas bases de estimación. Con esta aclaración en mente pasemos a los datos (cuadros 1-4), agregando que se reunieron los países (dentro y fuera del continente) según el lapso dominante del cual se cuenta con la información.

Más allá de las particularidades y limitaciones de la información, puede indicarse que la tendencia positiva observada hasta la década de los setenta y el posterior estancamiento o caída puede ser vinculado indudablemente al fin de lo que en Europa se señaló como "los treinta años dorados" y, en general, a la crisis del fordismo. En efecto, un rápido repaso puede incluir: a) la demanda de algunos países a Estados Unidos tendente a lograr la transformación de las reservas en dólares en su equivalente en oro, cuando el valor de éste todavía era de 35 dólares la onza trío; b) 
la decisión unilateral de Estados Unidos de producir una devaluación de su moneda de $1000 \%$ (llevando en ese momento la relación a 350 dólares la onza); c) la denominada crisis del petróleo — que elevó su precio sensiblemente a comienzos de los años setenta—, de la cual se emergió con un impresionante flujo financiero que en su momento fue denominado como "petrodólares"; d) el inicio del endeudamiento impulsado desde los países centrales para dar curso a tal excedente financiero internacional. En conjunto, dichos elementos dieron sustento a un proceso de fortalecimiento de los sectores propietarios frente al de los asalariados.

Cuadro 1

Participación de la masa salarial en el PIB, precios de mercado Comparación internacional 1935-2005

\begin{tabular}{rccccc}
\hline Año & Dinamarca & EU & Holanda & Japón & Taiwán \\
\hline 1935 & - & 50.88 & - & - & - \\
1940 & - & 52.04 & - & - & - \\
1945 & - & 51.02 a & - & - \\
1950 & - & 42.31 & - & $34.68^{b}$ \\
1955 & 53.08 & 42.50 & 40.23 & 37.55 \\
1960 & - & 54.77 & 45.22 & 39.16 & 37.36 \\
1965 & - & 56.25 & 50.78 & 43.25 & 39.33 \\
1970 & - & 55.68 & 54.19 & 43.10 & 41.71 \\
1975 & 51.49 & 59.85 & 58.81 & 53.64 & 45.52 \\
1980 & 54.47 & 58.57 & 52.06 & 52.72 & 46.90 \\
1985 & 55.24 & 60.11 & 51.72 & 51.96 & 50.44 \\
1990 & 52.73 & 57.69 & 51.05 & 54.59 & 52.79 \\
1995 & 54.64 & 58.23 & 50.68 & 54.32 & 52.19 \\
2000 & 52.69 & 57.53 & 50.79 & 54.82 & 50.59 \\
2001 & 52.68 & 58.20 & 51.34 & 53.82 & 48.68 \\
2002 & 53.76 & 58.21 & 51.53 & - & 49.24 \\
2003 & 54.12 & 58.11 & 51.07 & - & 48.57 \\
2004 & 54.12 & 58.02 & 49.87 & - & - \\
2005 & 53.18 & 57.16 & & & \\
\hline
\end{tabular}

Fuente: Graña (2006), cuadro 4.

Notas: a Corresponde a 1946; b corresponde a 1951.

Si analizamos algunas series en particular (cuadro 1), se destacan los valores de Estados Unidos, ubicados en general por encima del conjunto. Por otro lado, con el fin de la Segunda Guerra Mundial, la serie perteneciente a Holanda, después de una caída profunda en la inmediata posguerra, crece rápidamente hasta alcanzar los niveles de 
EU a principios de la década de los ochenta y luego presenta una tendencia negativa, terminando en cerca de $50 \%$. Si observamos los datos de Japón y Taiwán, vemos que la evolución es muy positiva hasta mediados de los setenta para el primer país y hasta principios de los noventa para el segundo. En cambio, Dinamarca mantiene su participación relativamente constante superando 50\% durante los últimos 40 años.

Cuadro 2

Participación de la masa salarial en el PBI, precios de mercado Comparación Internacional. 1970-2005

\begin{tabular}{cccccccc}
\hline Año & Alemania & Canadá & España & Finlandia & Francia & Italia & Norvega \\
\hline 1970 & 52.53 & - & - & - & - & 46.32 & 48.19 \\
1975 & 56.97 & - & 50.96 & - & - & 51.25 & 52.26 \\
1980 & 58.01 & - & 51.32 & - & 55.96 & 48.28 & 48.33 \\
1985 & 55.67 & - & 46.55 & - & 53.77 & 46.32 & 46.07 \\
1990 & 54.05 & - & 47.82 & - & 51.67 & 44.74 & 49.15 \\
1995 & 53.94 & 51.68 & 46.50 & 38.66 & 51.82 & 41.21 & 47.36 \\
2000 & 53.34 & 50.64 & 47.36 & 37.68 & 51.87 & 39.24 & 43.57 \\
2001 & 53.03 & 51.44 & 47.61 & 37.95 & 52.20 & 39.51 & 44.60 \\
2002 & 52.62 & 51.35 & 47.59 & 38.05 & 52.55 & 39.84 & 46.81 \\
2003 & 52.28 & 50.79 & 47.61 & 38.89 & 52.51 & 40.16 & 46.27 \\
2004 & 51.20 & 49.91 & - & 38.83 & 52.16 & 39.93 & 44.54 \\
2005 & 50.27 & - & - & 39.31 & 52.11 & 40.80 & 42.01 \\
\hline
\end{tabular}

Fuente: Graña (2006), cuadro 5.

En el cuadro 2 vemos que la participación alemana presenta una caída entre puntas como consecuencia de una tendencia negativa iniciada a principios de los años ochenta. Francia muestra, con algunas diferencias en sus niveles, una evolución muy similar, aunque en la última década la participación se ha mantenido prácticamente sin cambios. España, que tiene valores inferiores a los de estos últimos países, presenta una tendencia estable, después de una caída importante a principios de los ochenta. En cambio, el caso noruego presenta elevadas oscilaciones en sus valores, con picos hacia fines de los setenta, fines de los ochenta y nuevamente hacia fin de siglo, pero ha visto reducida su participación fuertemente en los últimos años (ocho puntos porcentuales —en adelante pp- desde 1998²). Con menor cantidad de datos, nos encontramos con las series de

2 De la fuente utilizada (Graña, 2006) aquí se transcribieron — por razones de espacio— - sólo los años terminados en 0 y 5 hasta 2000, inclusive. De allí en adelante, se tomaron todos los años. 
Canadá y Finlandia que muestran una estabilidad significativa, pero a niveles muy diferentes: la primera cercana a $50 \%$, la segunda aproximadamente $40 \%$. Italia es un caso bastante particular, ya que desde 1975 presenta una tendencia marcadamente negativa que reduce la participación más de 10 pp hasta llegar a 40\% en 2005.

\section{Cuadro 3a}

Participación de la masa salarial en el PIB, precios de mercado Comparación internacional 1980-2005

\begin{tabular}{|c|c|c|c|c|c|c|c|c|c|}
\hline \multirow[t]{2}{*}{ Año } & \multicolumn{2}{|c|}{ Argentina } & \multirow[t]{2}{*}{ Costa Rica } & \multirow[t]{2}{*}{ El Salvador } & \multirow[t]{2}{*}{ Honduras } & \multirow[t]{2}{*}{ Jamaica } & \multirow[t]{2}{*}{ México } & \multirow[t]{2}{*}{ Nicaragua } & \multirow[t]{2}{*}{ Panamá } \\
\hline & Mín. & Máx. & & & & & & & \\
\hline 1980 & 34.31 & 38.74 & 45.35 & - & 46.32 & - & 36.04 & - & 36.55 \\
\hline 1985 & 32.94 & 37.19 & 42.88 & - & 48.80 & - & 28.68 & - & 35.04 \\
\hline 1990 & 32.45 & 36.64 & 46.32 & 34.30 & 48.80 & 31.77 & 29.50 & - & 37.83 \\
\hline 1995 & 35.33 & 39.89 & 45.70 & - & 41.80 & 31.82 & 31.10 & 33.11 & 34.18 \\
\hline 2000 & 33.15 & 37.43 & 42.40 & - & 44.38 & 42.67 & 31.30 & 32.65 & 35.89 \\
\hline 2001 & 34.10 & 38.50 & - & - & 44.87 & 42.06 & 32.54 & - & 34.94 \\
\hline 2002 & 25.94 & 29.29 & - & - & 45.62 & 42.15 & 32.59 & - & 34.06 \\
\hline 2003 & 23.49 & 26.52 & . & - & - & . & 31.70 & - & 33.11 \\
\hline 2004 & 24.36 & 27.51 & - & - & - & - & 30.38 & - & - \\
\hline 2005 & 25.15 & 28.40 & - & - & - & - & - & - & - \\
\hline
\end{tabular}

Fuente: Graña (2006), cuadro 6.

\section{Cuadro 3b}

Participación de la masa salarial en el PIB, precios de mercado. Comparación Internacional. 1980-2005

\begin{tabular}{ccccccccc}
\hline Año & Bolivia & Brasil & Chile & Colombia & Paraguay & Perú & Uruguay & Venezuela \\
\hline 1980 & - & 34.70 & 38.10 & 32.54 & 39.42 & 29.69 & 35.59 & - \\
1985 & - & 38.42 & 35.60 & 31.77 & 35.07 & 27.45 & 38.11 & 39.94 \\
1990 & 34.88 & 45.40 & 33.80 & 29.21 & 27.53 & 26.66 & - & 34.87 \\
1995 & 33.02 & 38.30 & 35.40 & 35.00 & 31.94 & 25.19 & - & 35.76 \\
2000 & 36.06 & 37.90 & 40.43 & 35.52 & 38.76 & 24.49 & - & 32.85 \\
2001 & 36.01 & 37.04 & 40.66 & 35.09 & 38.60 & 24.59 & - & 35.15 \\
2002 & 35.19 & 36.14 & 40.48 & 35.41 & 37.88 & 24.06 & - & 33.05 \\
2003 & 34.43 & 35.61 & 39.39 & 34.03 & 34.38 & 23.70 & - & 30.69 \\
2004 & 30.85 & - & 38.68 & - & 32.77 & & - & 27.72 \\
2005 & 28.31 & - & - & - & - & & - & - \\
\hline
\end{tabular}

Fuente: Graña (2006), cuadro 7, con datos actualizados por la propia fuente.

\section{Desarrollo}


En estos cuadros ( 3 a y 3b) vemos la comparación con América Latina. La primera cuestión a remarcar es que ningún país supera el umbral de 50\% en los últimos 25 años. En segundo lugar, vemos que, con pronunciadas oscilaciones, los diferentes países no poseen distribuciones muy distintas, marcando una homogeneidad —al menos- en este periodo. Si nos concentramos en la década de los noventa (para la cual poseemos la mayoría de los datos) vemos que se presenta un comportamiento negativo a lo largo de toda la región. La importante caída entre 1993-1997 —que luego se verá para Argentina - se repite en Brasil, México y Venezuela (en este caso, la caída se detiene en 1996). ${ }^{3}$ Cuando se reinicia el ciclo descendente en la participación asalariada en Argentina hacia 1998, Brasil y Venezuela vuelven a registrar retrocesos en este indicador, mientras que México logra evitar la caída y crece marginalmente. El caso chileno de crecimiento durante casi toda la década de los noventa es una excepción quizá similar a la de Colombia que crece durante la primera mitad de la década pasada y luego se estanca hacia fin de siglo. A pesar de ello, los valores alcanzados no se diferencian de los de los demás países.

Sin embargo, no poseemos datos para comparar la situación latinoamericana con Argentina durante el momento más crítico de la crisis del régimen de caja de conversión (convertibilidad) y su abandono. Hacia mediados de la primera década del siglo XXI Argentina mostraba tener uno de los peores desempeños de los países analizados.

El panorama es otro si nos adentramos en la composición de la fuerza laboral. Resulta fácilmente comprensible que la participación salarial en el total de la renta disponible tiene relación con la importancia relativa del trabajo asalariado dentro de la ocupación total. Aquí también están presentes las dificultades en materia informativa. Con la cautela del caso y atendiendo las observaciones de la fuente, podemos tener un panorama regional que debe considerarse en paralelo con los datos precedentes. ${ }^{4}$

Hechas las debidas aclaraciones, se destacan los países del Cono Sur —más México- como los que cuentan con una proporción alta de personal en relación

Véase la nota precedente acerca de la serie completa.

4 Ciertamente estos datos son expuestos a título de referencia pues no debe olvidarse que se trata de información correspondiente al ámbito urbano de cada uno de los países en cuestión y también que han debido reunirse los valores de los asalariados con los del personal de servicio doméstico, ya que en algunos países se incluye a estos últimos entre los asalariados y en otros se los informa separadamente. 
Cuadro 4

Proporción de asalariados de América Latina Ocupación urbana 2005

\begin{tabular}{rccc}
\hline País & Asalariados & Servicio Doméstico & Total \\
\hline Chile & 69.1 & 6.5 & 75.6 \\
México & 74.8 & 0 & 74.8 \\
Argentina & 74.6 & 0 & 74.6 \\
Costa Rica & 68.7 & 4.9 & 73.6 \\
Panamá & 66.6 & 6.8 & 73.4 \\
Uruguay & 71.2 & 0 & 71.2 \\
Brasil & 61.5 & 8.5 & 70.0 \\
Paraguay & 51.2 & 11 & 62.2 \\
El Salvador & 57.9 & 3.9 & 61.8 \\
Ecuador & 55.4 & 5.2 & 60.6 \\
Rep. Dominicana & 54.5 & 4.9 & 59.4 \\
Guatemala & 54.2 & 3.7 & 57.9 \\
Venezuela & 57.8 & 0 & 57.8 \\
Honduras & 53.3 & 4 & 57.3 \\
Colombia & 49.3 & 5.1 & 54.4 \\
Perú & 46.2 & 5.2 & 51.4 \\
Bolivia & 45.6 & 4.6 & 50.2 \\
Nicaragua & 38.1 & 0 & 38.1 \\
\hline
\end{tabular}

Fuente: CEPAL, 2007.

de dependencia, dentro del total. Estos casos, que incluyen también a Costa Rica y Panamá, presentan valores que van de 75 a 70\% de participación asalariada en la ocupación urbana total.

Luego, bastante distanciados, se hallan varios países de Centroamérica y el Caribe junto con Paraguay, Ecuador y Venezuela. Este segundo grupo oscila en casi $60 \%$. Finalmente, un grupo de países andinos se ubica en las cercanías de 50\%. Por último, Nicaragua, en donde más de la mitad del empleo corresponde a trabajadores por cuenta propia. ${ }^{5}$

Evidentemente aquí no podemos profundizar en la variedad de situaciones sociales, económicas y políticas involucradas en estos casos. Sólo se pretende dejar planteada la necesidad de observar en simultáneo la participación en el ingreso y la

5 Bolivia, Colombia y Perú siguen en importancia por el empleo autónomo con valores próximos a $40 \%$.

\section{DeSarrollo}


composición del empleo. No obstante, tampoco se trata de postular relaciones lineales: la evidencia empírica está lejos de mostrar que los países con mayor proporción de ocupados asalariados son los que asignan a éstos mayor porcentaje del ingreso disponible. Si bien no hay un divorcio absoluto entre ambos fenómenos, en la determinación de la participación intervienen factores más complejos que intentaremos profundizar a continuación.

\section{Explorando las causas}

Un argumento esgrimido usualmente en distintos contextos para explicar el continuo deterioro de la situación socioeconómica de los trabajadores asalariados es el centrado en el constante incremento de mejoras tecnológicas que "desplazan" trabajadores y agilizan la movilidad del capital. De forma paralela se sostiene que hay lentitud en

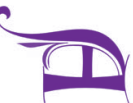
la respuesta de los sistemas educativos para adecuar la fuerza laboral a las mayores exigencias del ámbito de la producción.

A su turno se argumenta que la diferenciación creciente en el mundo de la producción genera compartimientos cada vez más estancos, por lo cual puede haber demanda insatisfecha de trabajadores en ciertos sectores y "sobrante" de ellos en otras actividades. Es lo que se ha dado en llamar segmentación o heterogeneidad laboral o productiva.

No se puede sostener sensatamente que éstos y similares argumentos explicativos no tengan algún grado de validez en la complejización de la problemática laboral y de la asignación de los ingresos sociales. Sin embargo, al ser tratados prescindiendo del contenido socioeconómico esencial terminan por constituirse, muchas veces, en argumentos de justificación antes que en conceptos de explicación.

En efecto, el punto nodal que ha quedado completamente marginado es aquel que relaciona la inequidad distributiva y el aparente sobrante de la fuerza laboral, por una parte, y con la manera y la cuantía en que se realiza la apropiación por parte de los factores productivos por la otra. En la matriz productiva básica predominante — característica de los dos o tres últimos siglos- es donde radica el núcleo problemático.

Veamos entonces este punto, antes de analizar qué pasa hoy en materia de empleo e ingresos.

Todo el andamiaje del liberalismo económico, una de las variantes de la economía neoclásica, se sostiene en alguna de las formas de la teoría del valor derivadas de las preferencias de los individuos y de un carácter singular del accionar de los agentes económicos. En dicho marco, el aporte al proceso productivo recibe una retribución 
equitativa, ya que la magnitud se corresponde con su respectiva productividad marginal. En tal caso, no hay lugar a pujas ni conflictos. Todo está en equilibrio, y en caso de no estarlo se llegará a él tarde o temprano.

No sólo Keynes desmitificó hace setenta años tal panacea ("en el largo plazo todos estaremos muertos"), sino que mucho antes Smith, Ricardo y Marx construyeron la economía política teniendo como pilar la identificación del trabajo como único creador de valor.

En el marco del proceso de producción de bienes y de servicios, actúan de consuno el capital y el trabajo. Y en tal "comunidad" aparentemente equitativa se define el carácter y la magnitud de lo que cada uno de ellos está en condiciones de percibir por su aportación.

De allí que resulte poco menos que insólito debatir acerca de la desigual captación de ingresos (y, por tanto, de acumulación de riquezas) entre distintos componentes de la población, sin atender al mundo de la producción como su generador prototípico.

Para mala fortuna, en América Latina —en general — y en Argentina —en particular - esta mirada ha quedado excluida del mundo del conocimiento y la reflexión socioeconómica. En su reemplazo se instaló un tema por demás calificado, como es el de la observación acerca de la manera en que se manifiestan las inequidades distributivas - ya sea entre las personas como entre los hogares_- pero que implícitamente desconoce aquél.

Desde ese lugar se ha contribuido a conocer la intensidad de los contrastes con indicadores como el coeficiente de desigualdad (de Gini u otros alternativos) o la brecha de ingresos entre los extremos superior e inferior de los perceptores. Si bien muchos de esos esfuerzos han procurado indagar sobre aspectos indudablemente intervinientes (llámese educación, entrenamiento laboral, etcétera), la característica dominante ha sido la ausencia completa de referencia a lo que aquí denominamos la matriz productiva.

En cierto modo ello estuvo condicionado por la ausencia casi absoluta de información relativa a la participación del salario en la distribución de la renta nacional o el producto generado en varios de nuestros países. No está por demás aclarar que tal ausencia es muy difícil de atribuir a la mera casualidad.

En efecto, durante décadas la única publicación oficial —en Argentina - que incluye información sistemática sobre la producción de riqueza, su aplicación económica y su apropiación por parte de los factores productivos databa de hace 30 años y cubre el lapso que va de 1950 a 1973. Sólo recientemente volvió a disponerse de datos oficiales aunque sin cubrir el dilatado lapso transcurrido y con cobertura y metodología diferentes. 
Lo expresado aquí no es simplemente una preocupación intelectual carente de asidero fáctico. Todo lo contrario. Si los problemas no estuvieran originados en el ámbito de la producción, entonces las políticas estatales mejor intencionadas sólo podrían transitar el camino de las acciones que procuran paliar las desigualdades. $\mathrm{O}$, como suele decirse en economía, sólo pueden plantearse acciones en el terreno de la distribución secundaria mediante la política fiscal (en cuanto a la captación de fondos públicos) y las políticas de atención social (en materia de aplicación correctiva o de protección de los sectores "desfavorecidos").

En otros términos, con esa tesitura se trataría de tener buenas ambulancias para recoger a los heridos de la sociedad tal como ésta funciona. El problema, por cierto, es que no habrá forma de encontrar tantas ambulancias como para atender a tan cuantioso número de afectados.

Por ello es importante reconocer o recuperar la noción de que las desigualdades tienen su germen principal en el proceso productivo mismo.

Ahora sí, como lo anunciamos, ilustremos lo aquí planteado con el caso de Argentina.

\section{Apuntes para una historia del trabajo y los ingresos en Argentina}

En la primera parte del siglo pasado en Argentina se fueron produciendo conflictos sociales de distinta envergadura así como fueron varios los núcleos de trabajadores más o menos organizados. Entre los censos de 1895 y 1914 la población se duplicó. Lo mismo ocurrió entre 1914 y 1947. Igual dinámica (duplicación intercensal) correspondió a la ocupación que alcanzó a algo más de seis millones de personas al término de la Segunda Guerra.

$\mathrm{Al}$ respecto, en otra ocasión he dicho que:

[...] (en la actualidad) la República Argentina no dispone de un sistema estadístico abarcador, capaz de dar cuenta temática y temporalmente de la evolución secular de las variables relevantes en la mayor parte de las cuestiones que nos propongamos analizar.

Las series estadísticas sobre empleo, desempleo, producción, productividad, ingresos, calificación de la fuerza laboral, y otros atributos del puesto de trabajo (categoría ocupacional, rama de actividad de la unidad económica, etc.) o de la persona (edad, género, nivel educativo alcanzado, etc.) se pueden calificar de insuficientes y/o escasamente aptos para tales propósitos. Las estadísticas ocupacionales, por caso, cubren por lo común o bien ciertos momentos (los siete Censos Nacionales levantados entre 1914 y 2001, inclusive), o bien sólo ciertos lapsos de manera relativamente continuada (la Encuesta Permanente de Hogares (EPH), que toma el último cuarto del siglo XX). Unas y otras, además, adolecen de no pocas diferencias metodológicas (entre sí e internamente) a través del tiempo. Algo similar ocurre con la información correspondiente a la medición de la actividad económica 
(producción, producto, valor agregado o ingreso) y de la captación de ingresos monetarios por parte de los partícipes en el proceso productivo (salarios, rentas, ganancia empresaria, ingresos por cuenta propia, etc.). ${ }^{6}$

Sin duda, un siglo atrás Argentina conformaba una sociedad en ebullición. El granero del mundo, una de las "potencias" de la época, había iniciado procesos de industrialización y de urbanización más intensos y con antelación a casi todo el continente.

La crisis de 1929-1930 encuentra al país con un importante nivel de actividad manufacturera. Antes y después de ese desequilibrio confluyen varios factores en la dirección de proporcionar mayor dinamismo a ese sector. Esa década y de inmediato la posterior configuran el periodo tradicionalmente identificado con el de la industrialización por sustitución de importaciones. Al respecto, Rapoport señala que, a diferencia de los años veinte - en los que el crecimiento pudo ser considerado como “espontáneo"-, en los treinta existía una política explícita (Rapoport, 2006:270). Dicha política económica se expresaba, entre otras cosas, en la larga lista de organismos de regulación económica que se constituyeron en el periodo.

Rapoport muestra que en los años treinta el salario real pone en evidencia un ciclo de declinación inicial con posterior recuperación de su valor, pero que empieza a mejorar significativamente durante los años de la guerra, anticipando el comportamiento favorable ulterior (ibidem).

Entre 1935 y 1946 la participación salarial en el ingreso no registra cambios significativos. Con algunas oscilaciones se arriba a 1942 como uno de los años de participación más baja (39\%), cifra que crece paulatinamente hasta llegar en $1946^{7}$ a $42 \%$ del ingreso bruto factorial. ${ }^{8}$ Estas cifras sugieren que mientras el empleo - particularmente el industrial — crecía velozmente, no ocurría lo mismo con la masa salarial, al menos en relación con el valor del conjunto de la riqueza generada.

Entonces llegamos a uno de los momentos cruciales de la historia argentina del siglo XX. Con base en una apretadísima síntesis de la literatura socioeconómica, al-

6 Lindenboim, 2007. Dicho capítulo sustenta gran parte de lo que sigue del presente texto. Allí se explica que hasta mediados de siglo el análisis socioeconómico no puede basarse en la distribución funcional, sino que debe aproximarse con el estudio del mercado de trabajo, en razón de la mencionada limitación de fuentes estadísticas, con base en la bibliografía referida en el capítulo en cuestión.

7 Al término de la conflagración internacional.

8 Secretaría de Asuntos Económicos, 1955. Como se verá luego, el relativo a la distribución funcional del ingreso es uno de los ámbitos con mayores dificultades informativas, tanto por los cambios metodológicos como por los periodos de ausencia de dato alguno. 
gunos de los rasgos característicos de este periodo serían los siguientes y algunos también controversiales.

El impulso originado en el cierre del comercio internacional durante la guerra habría sido uno de los principales "motores" del crecimiento industrial y, por extensión, del mejoramiento económico en un sentido más abarcador. La interrupción de los flujos de migrantes transoceánicos y su reemplazo por movimientos poblacionales internos habrían alimentado la fuerza laboral con nuevos y distintos contingentes. La irrupción desde el ámbito oficial de una estrategia social diferente (encarnada por el entonces coronel Juan Domingo Perón) completaba —al finalizar el conflicto bélicoun reencauzamiento económico, social y político. Allí se habría iniciado un periodo peculiar de "Estado de bienestar", sostenido en una fuerte industrialización (con el consiguiente incremento del empleo sectorial) y en el fortalecimiento del mercado interno (basado, en gran medida, en las más diversas formas de salario indirecto), todo lo cual dio origen a la constitución de una fuerza política de base popular que reemplazó con creces a la Unión Cívica Radical en la amplitud de su representatividad y cuyo arraigo y predominio se extendió a lo largo de la segunda mitad del siglo XX.

Más allá de los consensos, este esquema ha sido tanto aceptado como relativizado, por lo que es probable que merezca ser examinado, en particular, desde la perspectiva del mercado de trabajo. En este orden, la memoria colectiva guarda en su seno "evidencias" no siempre sostenidas adecuadamente, como veremos en seguida.

La inmediata posguerra se caracteriza por un alto crecimiento acumulado del producto (40\%), al menos respecto al correspondiente de la población (20\%). La ocupación en ese lapso crece algo menos (17\%) y, lo que es más llamativo, la masa de asalariados se incrementa aún más lentamente: sólo 15\% de aumento (Lindenboim, 2003:66-67), siendo éste uno de los aspectos poco tenidos en cuenta en la literatura respectiva.

Hacia el final de la guerra hubo un leve crecimiento de la participación del ingreso de los trabajadores en la renta total. Según la estimación de la Secretaría de Asuntos Económicos (SAE) de entonces, ello se modifica sustancialmente en los años inmediatos, al punto que en 1949 los asalariados superaron el 50\%.9

Podemos hacer un balance sintético: hay una mayor disponibilidad relativa de bienes y servicios (crecimiento mucho mayor del producto que de la población), con un leve descenso de la tasa de actividad (probablemente por la incidencia de la am-

9 Dicha serie es abandonada cuando el Banco Central elabora dos décadas después una nueva estimación para el periodo 1950-1973. 
pliación del régimen jubilatorio a partir de 1945). Al margen de la alta tasa de asalarización dentro de la fuerza laboral (tres cuartas partes del total, a lo largo del último medio siglo), la ocupación que más crece no es la del sector asalariado, sino la de los patrones y trabajadores por cuenta propia. En este magro desempeño asalariado, el mayor factor de crecimiento dentro de dicha categoría ocupacional es el de la industria (Lindenboim, 2003: 64-72; Marshall, 1981).

\section{En medio de la continua inestabilidad política argentina}

El análisis del mercado de trabajo argentino en el último medio siglo tampoco carece de dificultades para su materialización. Muchas de las afirmaciones difundidas a lo largo de tan extenso periodo pueden verse afectadas por dichos inconvenientes relativos a las fuentes. ${ }^{10}$

La gráfica 1 nos permite apreciar una dinámica económica bastante irregular. El ritmo de crecimiento económico fue deteriorándose hasta el comienzo de los años sesenta, década ésta que resultó de características positivas. Combinando la información de población, de producción y de empleo, podemos decir que algunos de los rasgos anotados para la inmediata posguerra (importante aumento del producto per capita, por ejemplo) se reproducen con fuerza en los sesenta, junto con un relativamente modesto crecimiento del empleo. Dicho lapso se inicia con la acción del (recién instalado) gobierno de Arturo Frondizi, el que abre una nueva etapa de crecimiento que, siendo aún de sustitución de importaciones, constituye un escalón distinto en el que

10 En 1991 se introdujeron cambios que no permiten una comparación consistente con los censos precedentes (entre otros puede consultarse al respecto a Giusti y Lindenboim, 1997). El censo siguiente, que debería permitir completar el análisis del siglo XX, sufrió demasiados inconvenientes durante su realización limitando mucho la utilización de sus resultados en estas materias. Respecto a los Censos Económicos, básicamente industriales, han tenido tantas modificaciones en sus criterios básicos (sobre la unidad económica, sobre los sectores relevados, sobre su clasificación sectorial, sobre la fecha de realización) que sus resultados poseen escasa comparabilidad, al menos tomados sus resultados tal como en su momento se han difundido (Lindenboim, 1984 y 1992). En materia de Encuestas a Hogares está cubierto un decenio inicial desde 1963 con la Encuesta de Empleo y Desempleo, reemplazada años más tarde por la — más conocida - Encuesta Permanente de Hogares. Esta última, luego de tres décadas, cambió su carácter semestral de captura de información por el denominado método continuo de relevamiento, publicándose de esa forma a partir de 2003. Las series de salario, nominal y real, a su turno son parciales y representativas sólo en el nivel de algunos sectores económicos. Por último, pero no por ello menos importante, en materia de distribución del ingreso entre los participantes en el proceso productivo (distribución funcional) existe una nefasta combinación de largos periodos sin información oficial y diversidad de criterios que han sido sucesivamente utilizados como se verá un poco más adelante. 
el capital extranjero y las actividades promovidas (petróleo, químicas, etcétera) son ahora los factores predominantes. Dicha nueva etapa se caracteriza también por un proceso de concentración económica ampliamente difundido.

Gráfica 1

Argentina. Crecimiento anual del Producto Interno Bruto (trienios móviles) 1948-1980

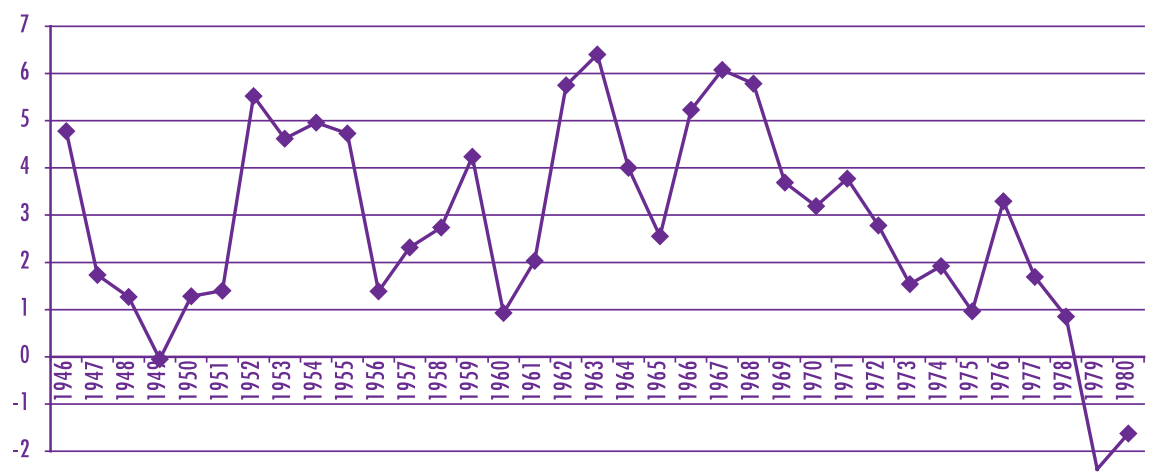

Fuente: Elaboración propia sobre la base de la Secretaría de Asuntos Económicos (1955), el Banco Central de la República Argentina (1975), la Comisión Económica para América Latina (1988) y la Dirección Nacional de Cuentas Nacionales (2006)

Sin embargo, al comenzar los setenta la tendencia se revierte. ${ }^{11}$ En ese decenio se deprime el ritmo de crecimiento económico y se mantienen tanto el aumento poblacional como el del empleo. Salvo un lapso de poco más de 30 meses, toda la década transcurre bajo regímenes de facto, cuyas características son harto conocidas en Latinoamérica, particularmente la dictadura iniciada en 1976 en Argentina. Incluso antes del golpe militar, en 1975 se inicia el experimento liberal que consistió en una muy fuerte devaluación del peso, contención salarial y vocación aperturista. Más allá de las contradicciones desatadas en ese momento, dicho episodio - conocido como el "rodrigazo"12 - fue el preámbulo de las políticas aplicadas no bien instalado el gobierno golpista en el otoño siguiente.

11 La gráfica 2 proporciona los elementos que sustentan estas afirmaciones. Esta sección, salvo indicación en contrario, se basa en Lindenboim, 2003:64-72 y sus respectivas fuentes.

12 En alusión al ministro de Economía de la presidenta María Estela Martínez de Perón, el ingeniero Celestino Rodrigo. 
La década de los años sesenta había sido el único periodo desde la finalización de la guerra en el que el número de los asalariados creció un poco más velozmente que el resto de las categorías ocupacionales. Recordemos que en la inmediata posguerra la menor dinámica del sector asalariado iba de la mano de una indudable relevancia del empleo asalariado industrial. En los sesenta, en cambio, el mayor impulso asalariado no contó a la industria entre sus promotores, ya que ésta sólo aportó $9 \%$ del nuevo contingente de trabajadores en relación de dependencia. Más de 40\%, en cambio, correspondió a los servicios, un cuarto al comercio y un quinto a la construcción (cuadro 5).

Gráfica 2

Argentina. Crecimiento intercensal de la población, el Producto Interno Bruto y el empleo 1947-1980

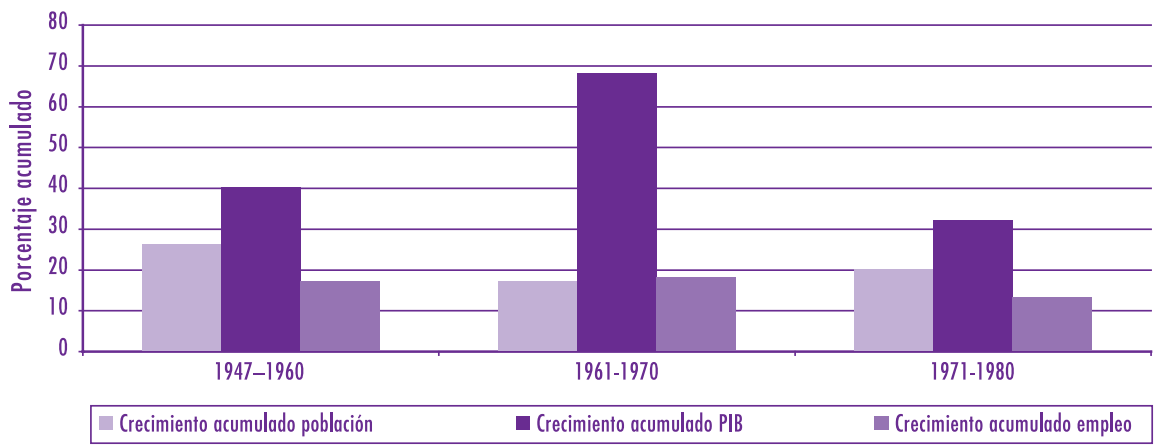

Fuente: Lindenboim, 2003: cuadro 1.

Cuadro 5

Argentina. Composición sectorial del crecimiento intercensal de asalariados

\begin{tabular}{crrrrrrrrrrr}
\hline Rama & Variac. & Agro & Minería & Industria & $\begin{array}{c}\text { Electricidad, } \\
\text { gas y agua }\end{array}$ & Const. & Com. & Transporte. & Fzas. & Serv. & Total \\
\hline $1947-60$ & $15 \%$ & $-39 \%$ & $1 \%$ & $47 \%$ & $9 \%$ & $24 \%$ & $2 \%$ & $21 \%$ & & $36 \%$ & $100 \%$ \\
$1960-70$ R1 & $23 \%$ & $4 \%$ & $1 \%$ & $9 \%$ & $1 \%$ & $19 \%$ & $26 \%$ & $-1 \%$ & & $42 \%$ & $100 \%$ \\
$1970-80$ R2 & $8 \%$ & $-21 \%$ & $0 \%$ & $24 \%$ & $1 \%$ & $11 \%$ & $38 \%$ & $-20 \%$ & $21 \%$ & $46 \%$ & $100 \%$ \\
\hline
\end{tabular}

Fuente: Lindenboim, 2003, cuadro 3.

Vale tener presente que entre mediados de los sesenta y de los setenta se verifica un periodo de crecimiento económico continuo, con una media de más de $4 \%$ anual. Es decir, que luego del interregno militar de 1962-1963 y su profunda crisis económica, 
el nuevo presidente Illía — surgido de elecciones con partidos proscriptos—inicia un ciclo económico positivo no sólo en las variables puramente económicas sino también sociales, pues desciende el número de desocupados, se recupera sensiblemente la participación del salario en el ingreso y se instaura el Salario Vital Mínimo y Móvil (Rapoport, 2006:478 y 542; Lindenboim et al., 2005:8). La década del sesenta podría caracterizarse por la aparente "reconstitución" de las relaciones capitalistas.

En los setenta el número de los asalariados crece de manera ínfima (8\%) y su composición se asienta en los servicios y el comercio, mientras que la industria vuelve a explicar un cuarto del aumento total. El agro (nuevamente) y el sector de los transportes son los expulsores netos de asalariados en ese decenio (cuadro 5).

En materia de empleo, fuera de los Censos de Población, la única posibilidad de observación reside en los datos que proporcionan los Censos Económicos. ${ }^{13}$ Dadas las limitaciones de su cobertura sectorial sólo podemos concentrarnos en la actividad industrial. Ya habíamos señalado que los componentes del crecimiento entre 1947 y 1954 estaban dados por el número de establecimientos y el personal no asalariado. Entre 1954 y 1964 hay una leve declinación de los establecimientos y de ambas categorías de ocupados. Desafortunadamente, la información posterior debe ser tomada con cautela, pues si bien abunda la literatura sobre el peculiar año 1974 en materia ocupacional y de ingresos laborales, el apoyo empírico genera no pocas dudas. ${ }^{14}$

En cuanto a lo acontecido en el periodo en materia de distribución del ingreso entre los factores productivos, nos remitimos a la gráfica $3 .{ }^{15}$ Los datos de principios de los años cincuenta se ubican en torno a 50\% de participación salarial con una tendencia a su disminución que continúa hasta el lanzamiento del plan de estabiliza-

13 Las limitaciones para las comparaciones entre censos industriales se encuentran en Lindenboim, 1984.

14 Si bien a la fecha del Censo Industrial (septiembre de 1974) se registra un número de asalariados de casi $25 \%$ superior al indicado por el relevamiento de 1964, los mismos datos censales revelan que en 1973 el promedio ocupacional era tan sólo 9\% superior al de una década atrás. Lo cual implicaría que en menos de un año el empleo asalariado industrial habría crecido a un ritmo de $15 \%$ — o sea una dinámica 15 veces superior a la de la década inmediata anterior- lo cual resulta poco plausible. Al mismo tiempo, la Encuesta Permanente de Hogares acababa de iniciarse y, por tanto, sus datos son limitados en cuanto no pueden cotejarse hacia atrás y, además, sólo cubrían algunas de las áreas urbanas más importantes. Finalmente, la serie oficial de distribución del ingreso llegaba hasta 1973 y hubieron de transcurrir décadas hasta que se dispusiera de nuevos datos avalados oficialmente.

15 Reiteramos la necesidad de no circunscribir el análisis a la información sobre participación salarial en la renta. 
ción del gobierno desarrrollista en 1959. Luego de la crisis política y económica de 1962-1963 se visualiza una mejora permanente de tal participación que, sin embargo, no logra al fin de la serie recuperar los valores iniciales.

Con toda esta información parece ratificarse la caracterización acerca de la década de los sesenta, que incluye un mayor crecimiento del empleo asalariado respecto a lo ocurrido en la inmediata posguerra, pero con una participación ínfima del componente industrial. También comprende un cambio en el peso relativo de patrones y cuentapropistas (en favor de estos últimos). Y principalmente incluye un continuo aumento de la actividad productiva pese a la gran inestabilidad política de ese periodo.

Gráfica 3

Argentina. Participación de la masa salarial en el PIB y costo de factores 1950-1973 (\%)

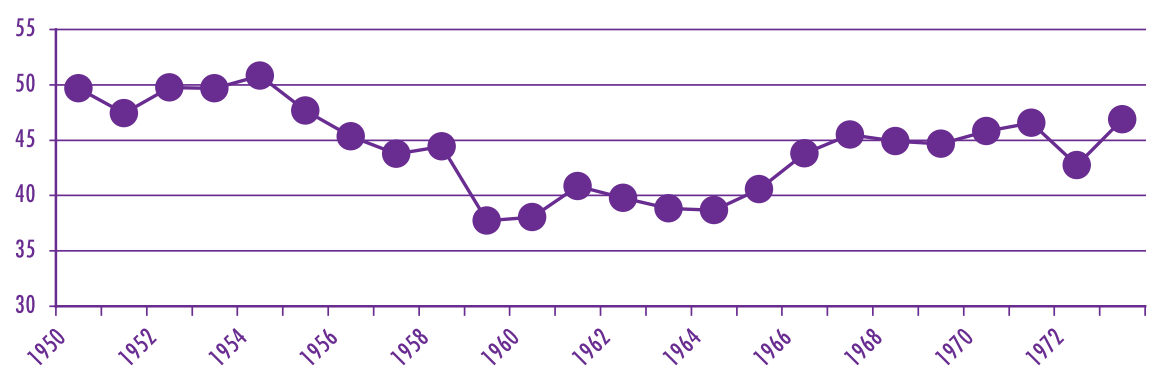

Fuente: Banco Central de la República Argentina, 1975.

Estos hechos, entre otros, son utilizados por algunos autores para expresar sus dudas acerca de la culminación de la etapa de sustitución de importaciones (Muller, 2002:156-168) que se suponía próxima a su agotamiento.

\section{El capitalismo argentino de fin de siglo ¿auge y ocaso del neoliberalismo?}

La cancelación de la discusión acerca del "agotamiento" de la estrategia sustitutiva iniciada en la década del treinta excede largamente los objetivos de este trabajo. En cambio, sí podemos decir que en materia ocupacional, como en un sentido socioeconómico más amplio, a mediados de la década de los setenta se impone — de manera harto violenta y conocida - una nueva estrategia que, para simplificar, llamaremos 
neoliberal. La misma engarza perfectamente con una escalada de enorme magnitud - y similar sentido - en buena parte de los países de América Latina y a escala mundial sostenida en lo que se conoce como Consenso de Washington.

En términos de empleo, ya hemos visto que el componente asalariado ha mantenido su participación relativa y que la industria aporta uno de cada cuatro nuevos puestos remunerados creados en los años setenta. La tasa de participación económica sigue disminuyendo por la caída de la de los varones — de 88\% en 1947 a 75\% en 1980 - si bien la de las mujeres continúa en alza: de $23 \%$ a $26 \%$ en igual lapso (Torrado, 2002:92).

En ese decenio el ajuste en el mercado de trabajo se basó en la disminución del salario real más que en la expulsión neta de trabajadores. La EPH muestra — desde su inicio en 1974 - un continuo descenso de la desocupación hasta 1980 en niveles bajísimos si se los compara con los que se verificaron desde mediados de los años noventa a esta parte.

En la década en cuestión se observaron comportamientos peculiares en más de un sentido. Por una parte, se hizo más visible el componente del empleo autónomo o por cuenta propia, aunque no haya sido ese el lapso de su mayor dinámica. Por otra parte, continuó el aumento de la oferta laboral de las mujeres. Ambos fenómenos habrían derivado - entre otros factores- del deterioro producido en los ingresos salariales. La caída en la participación del salario en el producto a costo de factores fue de 15 puntos porcentuales en 1976 respecto al año previo, recuperando hacia 1980 apenas dos terceras partes de tamaño quebranto (Llach y Sánchez, 1984).

La estrategia económica instalada desde entonces no fue revertida posteriormente, a despecho de la evaluación que pueda hacerse de los diversos intentos asociados con la recuperación democrática. La concentración económica, el permanente desplazamiento del papel orientador del Estado, el endeudamiento externo, la creciente apertura indiscriminada de la economía, el impacto negativo sobre la actividad productiva (calificado en más de una ocasión como de desindustrialización) con su derivación en las crecientes dificultades de la población por obtener una inserción laboral satisfactoria, la paulatina precarización de las condiciones de empleo remunerado y el efecto negativo sobre la participación salarial en el producto y sobre la capacidad de compra de ese salario, fueron características de las décadas recientes (Altimir y Beccaria, 1999; Damill, Frenkel y Maurizio, 2002). Al respecto, el incuestionable cambio favorable de las condiciones políticas a partir de 1983 — con la reconstitución del sistema democrático- o bien quedó en deuda o, directamente, se puede decir que profundizó tal proceso socioeconómico. 
Durante el último cuarto de siglo el comportamiento de la economía ha tenido oscilaciones mucho más intensas, como lo muestra la gráfica 4. En ese contexto, la inserción laboral de la población se hace extremadamente compleja y con el impulso proporcionado por la sucesión de normas — dictadas desde comienzos de los noventa - dirigidas hacia la flexibilización de los vínculos laborales se profundizan las condiciones de desprotección del sector asalariado. Según se desprende de la gráfica 5 , los últimos censos de población han dejado de ser apropiados para el seguimiento

Gráfica 4

Argentina. Crecimiento anual del Producto Interno Bruto (trienios móviles) 1983-2005

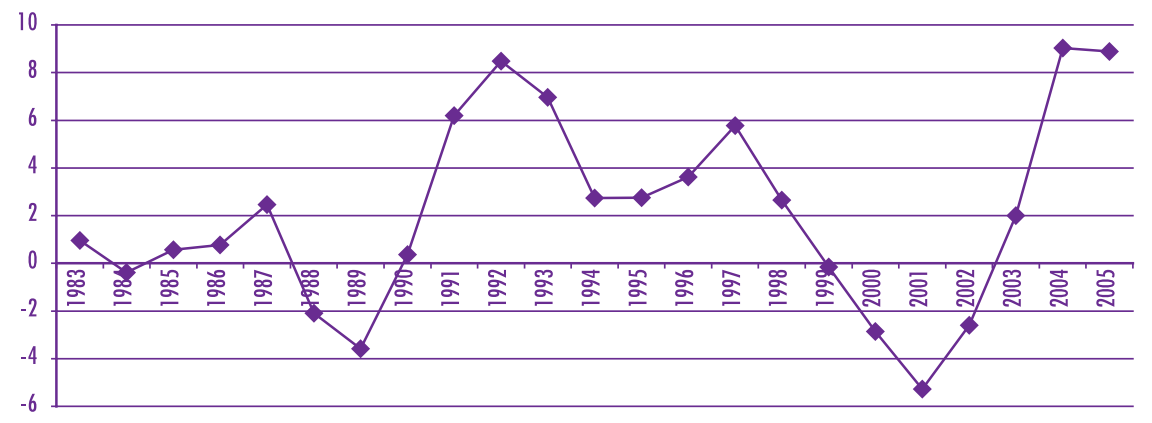

Fuente: Elaboración propia sobre la base de CEPAL (1988) DNCN (2006).

Gráfica 5

Argentina. Crecimiento intercensal de la población, el Producto Interno Bruto y el empleo 1980-2001

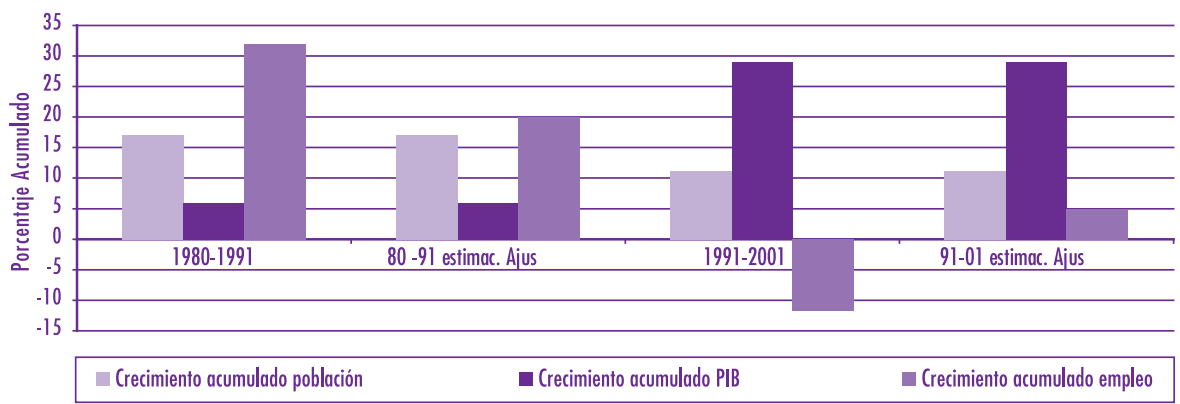

Fuente: Lindenboim, 2003 y elaboración propia sobre la base del Censo de 2001 y datos de la DNCN.

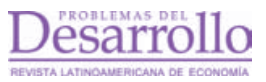

Vol. 39, núm. 153, abril-junio / 2008 
del mercado de trabajo. ${ }^{16}$ Por ello, para el periodo más reciente debemos circunscribirnos a los resultados de la EPH. Con base en ella podemos observar las características del crecimiento de la fuerza laboral (gráfica 6).

Gráfica 6

Argentina. Incremento medio anual de la PEA y sus componentes

1983-2001

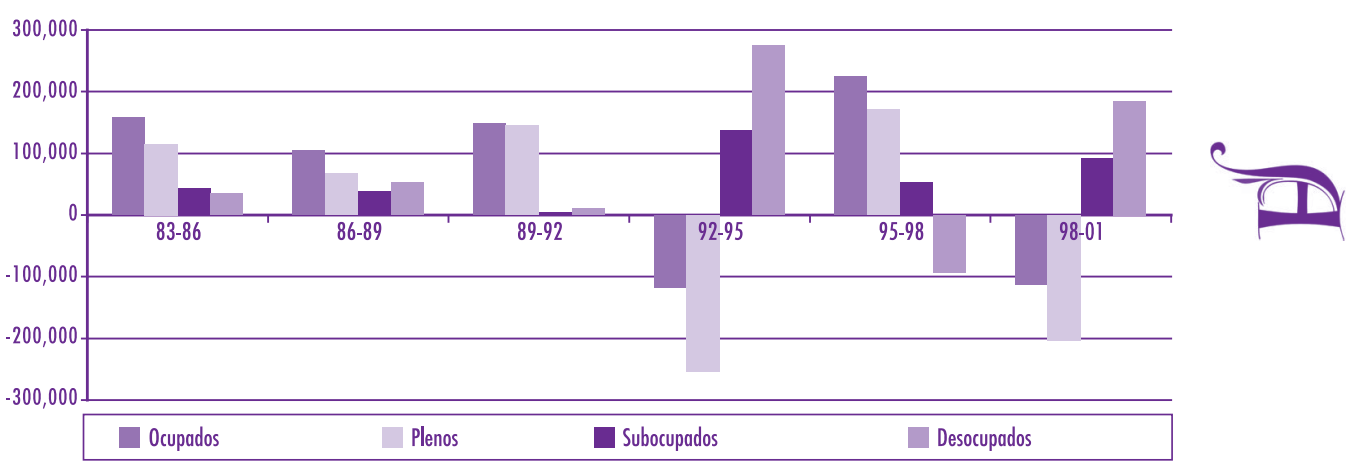

Fuente: Elaboración propia con base en EPH-INDEC.

Allí se destaca la diferencia de contenido del aumento de la población económicamente activa (PEA) en ambas décadas consideradas. En los años ochenta la subocupación registraba una presencia ínfima mientras que en los noventa se presenta como el rasgo dominante. El desempleo, por su parte, también difiere fuertemente entre ambos periodos.

En el cuadro 6 se observa que las fases de crecimiento económico no constituyeron garantía ni de absorción de empleo ni de una buena relación empleo-producto, mientras que los años recesivos agudizaban la mala calidad del empleo.

16 En la nota al pie 9 se indican las dificultades para la comparabilidad censal resultantes de los cambios introducidos en el Censo de 1991. Posteriormente, el relevamiento de 2001 sufrió los efectos de dificultades diversas en su preparación y ejecución. Los ajustes que deben ser realizados a los resultados oficiales en materia de participación ocupacional de la población, en el mejor de los casos, pueden servir para modificar los valores globales de la ocupación, pero no permiten homogeneizar con el pasado componentes tan relevantes como las categorías ocupacionales, las ramas de actividad y otros atributos. 
Cuadro 6

Argentina. Evolución del producto y el empleo en la década de los noventa

\begin{tabular}{lccccc}
\hline & \multicolumn{5}{c}{ Variaciones porcentuales } \\
\cline { 2 - 6 } & PIB & Empleo & Subempleo & Empleo pleno & Empleo/PIB \\
\hline 1991 & $10.5 \%$ & $3.7 \%$ & $-8.5 \%$ & $5.0 \%$ & 0.4 \\
1992 & $9.6 \%$ & $2.6 \%$ & $6.2 \%$ & $2.3 \%$ & 0.3 \\
1993 & $5.7 \%$ & $1.1 \%$ & $18.4 \%$ & $-0.6 \%$ & 0.2 \\
1994 & $8.0 \%$ & $-2.0 \%$ & $13.4 \%$ & $-3.7 \%$ & -0.2 \\
1995 & $-4.0 \%$ & $-1.7 \%$ & $24.6 \%$ & $-5.3 \%$ & 0.4 \\
1996 & $5.5 \%$ & $1.6 \%$ & $10.7 \%$ & $0.0 \%$ & 0.3 \\
1997 & $8.1 \%$ & $7.2 \%$ & $-0.5 \%$ & $8.7 \%$ & 0.9 \\
1998 & $3.9 \%$ & $2.7 \%$ & $5.7 \%$ & $2.1 \%$ & 0.7 \\
1999 & $-3.4 \%$ & $1.4 \%$ & $6.9 \%$ & $0.4 \%$ & -0.4 \\
2000 & $-0.5 \%$ & $0.4 \%$ & $4.8 \%$ & $-0.5 \%$ & -0.8 \\
2001 & $-4.4 \%$ & $-4.1 \%$ & $11.1 \%$ & $-7.2 \%$ & 0.9 \\
\hline
\end{tabular}

Fuente: Lindenboim, 2003, cuadro 7.

A su turno se observa el resultado para todo el periodo en cuanto a la importancia del desaprovechamiento socioproductivo de la fuerza laboral (gráfica 7).

Un ejemplo palmario de ello es el incremento de los empleos precarios cuyo ritmo fue varias veces superior al de los protegidos. Con ayuda del cuadro 7 podemos mirar con mayor detalle lo acontecido en la década de los noventa. El empleo

Gráfica 7

Argentina. Tasas de desocupación y de subocupación (\%)

Área urbana 1983-2001

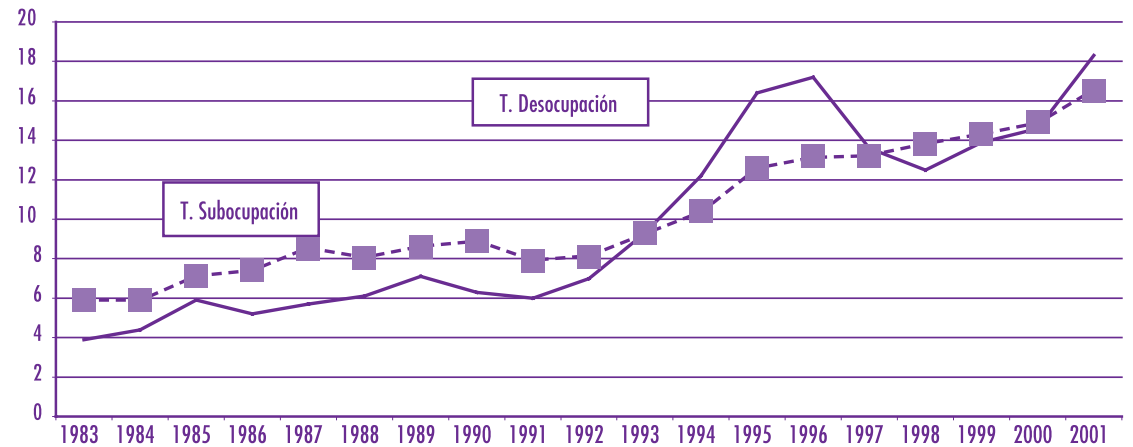

Fuente: Elaboración propia sobre la base de EPH-INDEC, ondas de octubre.

\section{Desarrollo}


Cuadro 7

Argentina. Cambio en el empleo asalariado urbano, según la calidad del vínculo Diez aglomerados seleccionados, 1991-2001

\begin{tabular}{lccc}
\hline \multirow{2}{*}{ Ramas } & cambio total & \multicolumn{2}{c}{ Explicado por } \\
\cline { 3 - 4 } & & Protegidos & Precarios \\
\hline Manufactura (con EGA) & -32.9 & -29.1 & -3.8 \\
Construcción & -11.8 & -15.9 & 4.1 \\
Comercio & 30.4 & 7.5 & 22.9 \\
Transporte, comunicaciones y servicios conexos & 36.1 & -1.6 & 37.7 \\
Servicios financieros e inmobiliarios & 24.8 & 18.2 & 6.6 \\
Administración pública y defensa & 24.2 & 1.5 & 22.8 \\
Enseñanza, servicios sociales y comunitarios & 20.5 & 12.9 & 7.6 \\
Servicio doméstico & 28.9 & -1.9 & 30.7 \\
Otros (1) & -30.8 & -0.2 & -30.7 \\
Total & 7.5 & -3.3 & 10.8 \\
\hline
\end{tabular}

(1) Se incluyen actividades primarias, servicios personales y sin especificar.

Fuente: Elaboración propia sobre la base de EPH-INDEC. Onda octubre 1991 y octubre 2001.

asalariado creció $7 \%$ debido a un alza mayor del empleo precario y una pérdida de $3 \%$ del protegido.

En el nivel sectorial se puede ver que la industria perdió uno de cada tres asalariados, pérdida explicada casi en su totalidad por el empleo protegido. Otro sector que disminuyó su dotación fue el de la construcción (-11,8\%) por la caída del empleo protegido compensado en parte por un incremento del empleo precario. La rama que más creció fue la del transporte (más de 35\%), pero ese aumento se basó en la creación de puestos de mala calidad. Un caso singular es el del empleo en la administración pública que aumentó en casi 25\%, de lo cual en su mayoría todos fueron empleos precarios. Es decir, desde el Estado no sólo se dictaban las normas que dejaban sin protección a los asalariados sino que, además, las ponía en práctica en sus propias dotaciones.

En todo caso, estos mecanismos de empeoramiento de la calidad de los puestos de trabajo asalariado ${ }^{17}$ probablemente explican que en la última década del siglo XX,

17 Sin desmedro del papel nefasto de las políticas de los noventa, debe recordarse que el empleo no protegido, que a fines del siglo XX llegó alrededor de 40\% del empleo asalariado, era en los comienzos de los noventa del orden de $30 \%$ y diez años antes rondaba en $20 \%$. Es decir que — desafortunadamente — tiene una historia prolongada. 
pese a la intensidad de las sucesivas crisis, el empleo autónomo no haya aparecido como opción "de ajuste” tal como ocurrió en periodos anteriores (Monza, 2000).

Como corolario digamos que luego de un largo periodo en que se careció de información oficial sobre la apropiación factorial del ingreso, la Dirección Nacional de Cuentas Nacionales (DNCN) difundió en 2006 una estimación basada en una nueva metodología referida al periodo 1993-2005.

De cualquiera manera, dado que no es éste el lugar para introducirnos en pormenores al respecto, digamos que esta serie oficial muestra la caída continua en la primera mitad de la década de los noventa y una recuperación ulterior (gráfica 8). ${ }^{18}$

Luego de 2001, ${ }^{19}$ la recuperación reciente es tenue en relación con la profundidad de la caída (ambos movimientos son más suaves en la estimación oficial que en la del $\mathrm{CEPED}^{20}$ ). Como síntesis, de los poco más de 10 puntos porcentuales que perdieron los asalariados entre 1993 y 2003, hasta el momento pudieron recuperarse menos de la mitad, o, en otros términos, aún no pudo volverse a los valores registrados en el cambio de siglo.

Gráfica 8

Argentina. Participación del salario en el producto (precios básicos).

Porcentajes, 1993-2005

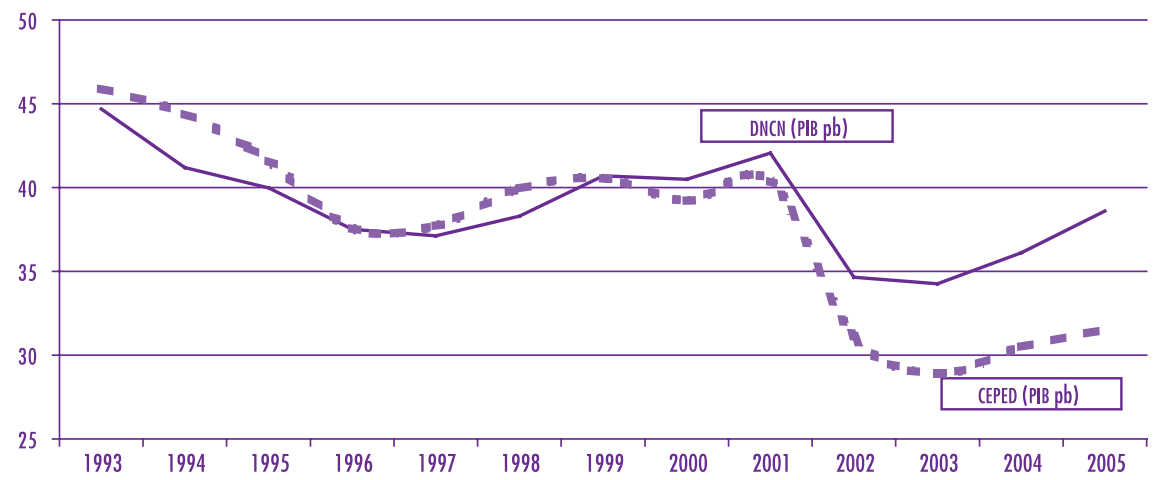

Fuente: DNCN, 2006 y Lindenboim et al. (2005) con datos actualizados.

18 La metodología utilizada en la elaboración del CEPED se detalla en Lindenboim, J. et al. (2005).

19 El "pico" en 2001 se explica porque ese año el producto cae mucho más intensamente que el empleo y los salarios.

20 En Lindenboim et al. (2006) se indican los posibles factores explicativos de tales discrepancias.

\section{Desaarrollo}


Una manera de visualizar esto en un contexto de largo plazo consiste en tomar una serie de salario promedio por décadas, como se ve en la gráfica 9. De allí puede señalarse que los valores van creciendo desde los años cuarenta hasta los setenta y a partir de ese momento no han dejado de descender, para arribar en los primeros años del siglo XXI a valores parecidos a los vigentes en los años cuarenta (Maurizio, 2007).

Puede decirse que, en materia socio-ocupacional, el siglo XX difícilmente podría concluir en Argentina de manera más preocupante. Con la mirada de largo plazo vemos que si bien no hay dudas de que el aumento del desempleo ha sido un factor decisivo en el alza de los niveles de pobreza, esta última ha venido expandiéndose aún antes de la estampida de la desocupación en los años noventa. La gráfica 9 confirma que el punto nodal está en el modo en que se realiza "el reparto de la torta", del cual depende la capacidad real de compra de las remuneraciones del trabajo.

Gráfica 9

Argentina. Evolución del salario real (base 1970 = 1)

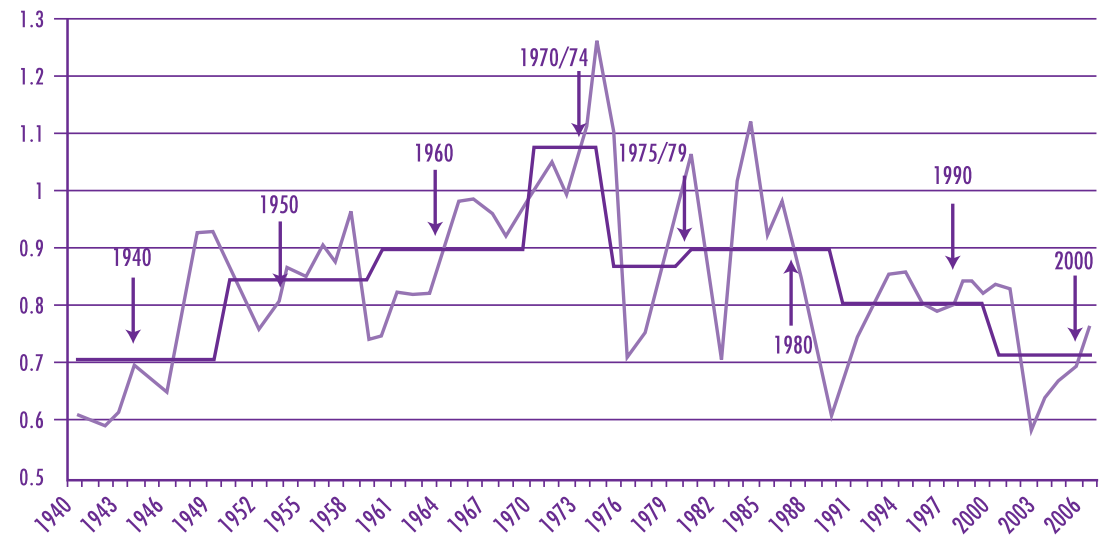

Fuente: Maurizio, 2007:4.

\section{¿Cuál es la situación a comienzos del siglo XXI?}

El recorrido hecho a lo largo de esta centuria para el caso de Argentina no es nítido en cuanto al balance final del periodo en cuestión. En particular, porque a poco de atravesar una de las crisis más profundas tanto en su dimensión económica como en la social y la política, el país se encuentra, promediando la primera década del siglo XXI, con evidentes signos de mejoramiento y recuperación. La cuestión relevante es indagar en la certeza de su solidez. 
Enumeremos entonces algunos rasgos actuales. La estructura sectorial del empleo refleja, en gran medida, la circunstancia de que estamos hablando de una sociedad eminentemente urbana, pues alrededor de $90 \%$ de su población reside en aglomeraciones que tienen un mínimo de 2,000 habitantes. Coincidentemente además, según el Censo de Población de 2001, ${ }^{21}$ apenas 9\% de los ocupados se desempeña en las actividades primarias. El empleo industrial, que alcanzó en otras épocas un cuarto del empleo total, inicia el siglo XXI con una participación de 12\%. Adicionando los sectores electricidad, gas y agua y construcción se totaliza en $28 \%$, lo que significa que las actividades comerciales y de servicios absorben más de 70\% del empleo total censado. La misma fuente pone en evidencia que el componente asalariado representa $70 \%$ y el empleo autónomo $20 \%$, restando valores mínimos para las categorías de patrones y familiares sin remuneración. En este sentido, es por demás relevante que, aun después de las fuertes transformaciones del aparato productivo, el sector del trabajo en relación de dependencia se haya mantenido en el mismo rango de participación porcentual de las últimas décadas. ${ }^{22}$

Desde el punto de vista de la situación en el ámbito urbano cubierto por la EPH, la discriminación puede hacerse con algún detalle mayor. La gráfica 10 muestra que el empleo no asalariado (empleadores y trabajadores por cuenta propia) representa un cuarto del total a comienzos de 2007. Es decir, que el sector asalariado alcanza tres cuartas partes de los ocupados. Ese porcentaje está integrado por asalariados que gozan de la protección de las normas laborales (46\%); por asalariados privados precarios (21\%), además del personal del servicio doméstico (8\%) y de los beneficiarios de los planes sociales vigentes. ${ }^{23}$

Si bien la proporción de asalariados desprotegidos aún es extremadamente alta (en torno a 40\% del total del personal en relación de dependencia), la dinámica de creación de empleo ha cambiado en los años iniciales de este siglo. En efecto, el cuadro 8 pone en evidencia una variación apreciable en el volumen de empleo creado y en la calidad del vínculo de los asalariados que se incorporan a la fuerza laboral. La industria, que había perdido una proporción importante de sus asalariados en los noventa, ahora los incrementa en $44 \%$ y, lo que es más importante, con una baja proporción de formas precarias en la contratación de trabajadores.

21 Ya se indicó que la evaluación de la calidad de tal censo abre interrogantes no marginales.

22 Más aun cuando los cambios metodológicos tienden a desfavorecer (comparativamente con los censos anteriores a 1991) la importancia relativa de los asalariados.

23 Estos porcentajes refieren al universo de los ocupados. 
Gráfica 10

Argentina. Composición (\%) de los ocupados urbanos. ${ }^{24}$ Todos los aglomerados Primer trimestre de 2007

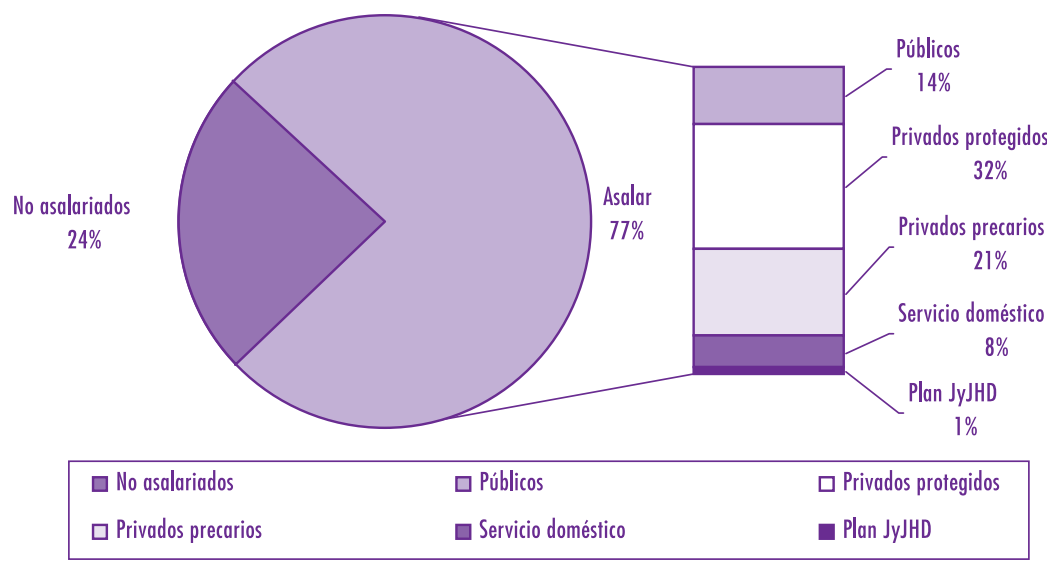

Fuente: Elaboración propia sobre la base de la EPH, total aglomerados, primer trimestre de 2007.

Claro que esto no se repite en el resto de los sectores. No sólo en el servicio doméstico — donde sigue primando la incorporación de asalariados sin coberturasino en ramas con alta creación de puestos de trabajo, como la construcción. Tanto en comercio como en servicios financieros e inmobiliarios cerca de uno de cada tres nuevos trabajadores es precario.

Deben ser hechas algunas reflexiones antes de concluir este tránsito sobre la fuerza de trabajo en Argentina en gran parte del siglo XX y comienzos del actual. Una de ellas alude a la dinámica de la incorporación de nuevos contingentes a la población activa. Al cambiar el siglo en el mercado de trabajo urbano se ponía en evidencia una tasa de desocupación extraordinariamente alta (en sí misma y en contraste con los datos históricos) superando 20\% en 2002-2003. Luego se fue atemperando significativamente, al punto que al escribir estas líneas la tasa de desocupación ronda $10 \%$, siendo notoria la dificultad de que tal indicador retorne a los bajos valores del pasado. ${ }^{25}$ Ello expresa que la economía del país se ha mostrado claramente incapaz

24 Debe notarse que aquí se incluye a los beneficiarios de planes sociales que realizan contraprestación laboral. Su peso en el total captado por la EPH, en todo caso, es ínfimo.

25 Si volvemos al gráfico 7 , podemos observar que en los años ochenta la tasa de desempleo era relativamente baja alcanzando un pico de 7\% en plena hiperinflación en 1989. 
de absorber de manera satisfactoria la fuerza de trabajo potencial de la que dispone. Este contraste no ha sido más intenso debido a la sensible disminución del ritmo de crecimiento poblacional. De tal manera, la supresión o morigeración significativa de las formas visibles de desaprovechamiento productivo de sus habitantes (el desempleo y el subempleo) debieran ser tareas prioritarias en la agenda de la región, de cuya independencia se cumplen dos siglos.

\section{Cuadro 8}

Argentina. Cambio en el empleo asalariado urbano, según calidad del vínculo Todos los aglomerados II trimestre 2003-I trimestre 2007 (\%)

\begin{tabular}{lccc}
\hline & Cambio total & \multicolumn{2}{c}{ Explicado por } \\
\cline { 3 - 4 } & & Protegidos & Precarios \\
\hline Manufactura (con EGA) & 44.3 & 38.4 & 6.0 \\
Construcción & 119.5 & 54.2 & 65.3 \\
Comercio, restaurantes y hoteles & 44.3 & 30.5 & 13.8 \\
Transporte y comunicaciones & 18.9 & 22.4 & -3.5 \\
Serv. financieros e inmobiliarios & 40.0 & 28.9 & 11.1 \\
Adm. pública y defensa & 34.9 & 33.2 & 1.8 \\
Enseñanza, salud, servicios sociales & 16.4 & 14.4 & 2.0 \\
Servicio doméstico & 30.8 & 6.8 & 24.0 \\
Otros (1) & 5.7 & 7.6 & -1.8 \\
Total & 34.9 & 24.9 & 10.0 \\
\hline
\end{tabular}

(1) Incluye las actividades primarias, los otros servicios sociales y comunitarios y las actividades no especificadas.

Fuente: Elaboración propia sobre la base de EPH-INDEC (no incluye beneficiarios de planes).

Otro aspecto que indudablemente trasciende el campo de la inserción laboral —que lo influye notablemente - es el relativo al constante incremento de la productividad del trabajo en la economía. ${ }^{26}$ Dicho crecimiento es un requisito imprescindible para garantizar la ampliación de la dotación de bienes y servicios accesibles para la población y para permitir una satisfactoria inserción en el contexto internacional.

En la gráfica 11 se ilustra el dispar comportamiento de la productividad del trabajo en relación con el costo laboral empresarial. En pocas palabras, tanto en los

26 Un trabajo reciente alude a estos aspectos (Feliz y Pérez, 2004).

\section{Desaarrollo}


noventa como en los años recientes de alto ritmo de crecimiento, el aumento de la productividad fue indudable. Sin embargo, el salario perdió importancia relativa en los costos empresarios, lo cual habla del margen significativo existente para una efectiva recuperación de la capacidad adquisitiva de los ingresos laborales.

Gráfica 11

Evolución del PIB, productividad y costo laboral. 1993-2006. $1993=100$
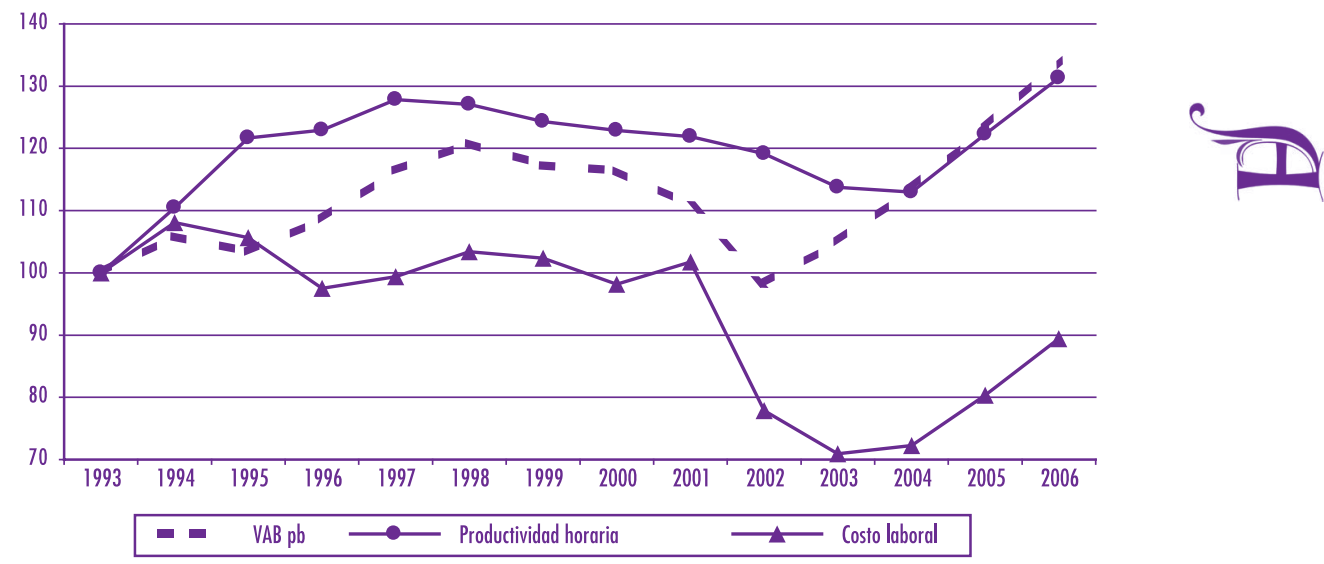

Fuente: Lindenboim et al. (2007) con base en EPH-INDEC y DNCN-INDEC.

Esto se conecta con la dinámica de absorción ocupacional. En efecto, en los primeros años del siglo XXI, la elasticidad empleo-producto alcanzó — por momentosvalores muy acrecentados. Pero una elevada elasticidad no es más que la equivalencia a un incremento modesto en la productividad del trabajo. Por tanto, mientras se puedan mantener las elevadas tasas de crecimiento de los años recientes se hará menos conflictivo el ritmo de cambio de la productividad.

Sin embargo, ese buen ritmo de crecimiento económico requiere de un proceso de inversión que implica una tendencia hacia una menor demanda relativa de trabajo. $\mathrm{He}$ aquí un conflicto sobre el que pocas veces se ha puesto el acento adecuadamente, el cual configura otro aspecto crucial en la agenda hacia el inicio de la tercera centuria de Argentina y, seguramente, en todo el continente. Cuando en más de una ocasión se ha dicho que las metas de empleo deben ser parte de los objetivos generales de orden macroeconómico, se está haciendo referencia a estas cuestiones que requieren 
un procesamiento social y político adecuado para arribar a acuerdos que garanticen el progreso general y la protección de los sectores más vulnerables.

Esto lleva de lleno al tema de la distribución del ingreso en términos no sólo de ética social y de viabilidad política. El siglo XX ha mostrado a una sociedad argentina en la que la mejor participación salarial fue de la mano de una menor inequidad y ello configuró - durante décadas - una parte esencial del carácter comparativamente menos desigual en el concierto de América Latina. Hoy los signos de injusticia son altamente irritantes y quizá debiera prestarse más atención a la vinculación que ésta tiene con el modo en que la riqueza es creada y repartida, esto es, el modo en que capturan asalariados y no asalariados los resultados de la producción misma. En otros términos, querida o no, la contraposición entre los sectores del capital y el trabajo está presente. El ahorro relativo de trabajo es la aspiración del capital y, al mismo tiempo, es requisito para la mejora a largo plazo de las condiciones sociales de reproducción de la población. De tal modo, es imperativo diseñar mecanismos que estimulen el avance tecnológico pero, al mismo tiempo, que garanticen que sus beneficios sean apropiados no sólo por los propietarios de las empresas. Ello en virtud de elementales criterios de equidad pero también debido a la necesidad de sustentabilidad del propio sistema dominante. No es vano recordar que América Latina tiene el triste privilegio de ser la región más desigual y seguramente entre sus determinantes centrales se cuente este particular estilo de apropiación.

\section{A manera de colofón}

No hay dudas acerca de la relevancia de la experiencia argentina en los primeros años de esta centuria, para sí misma como sociedad y para el conjunto de la región. El notable reflujo de los excepcionales niveles de desempleo y subempleo alcanzados en torno del estallido de la convertibilidad es, probablemente, una de las mejores noticias dentro del panorama socioeconómico reciente. Mientras en los años ochenta el promedio de desempleo estuvo en el orden de 5\%, en 1994 se superó la marca de 10\% y el promedio en la segunda mitad de esa década estuvo cerca de 15\%, la superación de $20 \%$ en medio de la crisis de 2002 marcó uno de los peores momentos en la materia.

La modificación del tipo de cambio (suprimiendo la artificial sobrevaluación de la moneda local), la fuerte demanda internacional de bienes primarios - en particular la vinculada con la soja-, la suspensión de los pagos de capital e intereses de la abultada deuda externa, el establecimiento de retenciones a algunas exportaciones y la formulación de un plan compensatorio para los sectores más vulnerables permitieron, desde mediados de 2002, iniciar un intenso proceso de recuperación, el cual 
- gracias a su continuidad (e incluso profundización) por el gobierno instalado en 2003 - dio lugar a que en pocos años se recuperara el nivel de actividad económica alcanzado en 1998, al tiempo que se incorporaban anualmente centenares de miles de trabajadores al mercado laboral. Aun con retrasos, se verificó en ese marco una recuperación de los niveles salariales estancados durante los noventa y fuertemente deprimidos en términos reales con la crisis, discutiéndose en la actualidad si se recuperó o no la capacidad de compra de 2001.

Sin embargo, esta nueva situación puso en evidencia una vez más el equívoco en que cayó gran parte de la sociedad argentina al asumir que los problemas de pobreza e inequidad se originaban exclusivamente en la falta de oportunidades laborales. ¿Quién puede dudar que ello ha contribuido a agravar el problema? Pero se advierte que habiendo avanzado notablemente en materia ocupacional, la lentitud en modificar la enorme disparidad en la percepción de ingresos tiene menos relación hoy con el desempleo que con los niveles con los que son retribuidas las tareas desempeñadas por los asalariados.

Del contenido de estas páginas puede derivarse que la escasa participación del salario en la apropiación de la renta global es no sólo un signo de inequidad sino que también se configura como el obstáculo real o potencial para el propio crecimiento económico. En otras palabras, aquí se dice no sólo que es un imperativo ético remediarlo, sino que además su no resolución traerá aparejado, más temprano que tarde, un freno a la sustentabilidad del crecimiento económico, con lo que volveríamos a un ciclo en el cual la disminución de la demanda de fuerza laboral acrecentaría nuevamente las evidencias de desigualdad que aún subsisten en grado preocupante.

Y esto es anterior, sin lugar a dudas, a los mecanismos que las instituciones estatales pueden $-\mathrm{y}$ deben — poner en marcha en aras de morigerar las desigualdades vigentes.

Pero la ilustración con el caso argentino, en esta oportunidad, pretende señalar un condimento de relevancia para el análisis de la situación socioeconómica regional y sus perspectivas.

Son abundantes las evidencias acerca del carácter desigual de nuestras sociedades. América Latina, se sostiene con razón, es la región del mundo con mayor desigualdad. La brecha de ingresos de las familias, por no hablar de los contrastes en los patrimonios, nos otorga un triste privilegio. Precisamente el punto neurálgico, en nuestra opinión, es discutir más profundamente acerca de las diversas razones que generan inequidades de tamaña intensidad. De manera destacada allí se ubica lo relativo a la apropiación factorial del ingreso. 


\section{Bibliografía}

Altimir, Óscar y Luis Beccaria, El mercado de trabajo bajo el nuevo régimen económico en Argentina, Serie Reformas Económicas núm. 68, Santiago de Chile, ONU, 1999.

Banco Central de la República Argentina, Sistema de cuentas del producto e ingreso de la Argentina, Buenos Aires, 1975.

CEPAL, Estadísticas de corto plazo de la Argentina: cuentas nacionales, industria manufacturera y sector agropecuario pampeano, Documento de trabajo núm. 28, Buenos Aires, CEPAL, 1988.

, Proyecto de revisión de las cuentas nacionales y de la distribución del ingreso, Buenos Aires, Informe final de la CEPAL, 1991.

, Anuario Estadístico de América Latina y el Caribe, 2006, Santiago de Chile, 2007.

Damill, Mario, Roberto Frenkel y Roxana Maurizio, Argentina. Una década de convertibilidad. Un análisis del crecimiento, el empleo y la distribución del ingreso, Santiago de Chile, OIT, 2002.

Dirección Nacional de Cuentas Nacionales (DNCN), www.mecon.gov.ar.

Feliz, Mariano y Pablo Pérez, "Conflicto de clase, salarios y productividad. Una mirada de largo plazo para la Argentina", en Neffa, Julio y Robert Boyer (coordinadores), La economía argentina y su crisis (1976-2001): visiones institucionalistas y regulacionistas, Buenos Aires, Miño y Dávila Editores, 2004.

Giusti, Alejandro y Javier Lindenboim, "Cambio 'técnico' en el censo de 1991: cuantificación de su efecto en las tasas de actividad y evaluación de los resultados sobre las características económicas de la población", en Actas de las IV Jornadas de Población de AEPA, Resistencia, AEPA, 1997.

Graña, Juan Martín, Distribución funcional del ingreso en la Argentina. 1935-2005, Informe final de Beca UBACYT, Buenos Aires, FCE-UBA, 2006.

Lindenboim, Javier, Damián Kennedy y Juan Martín Graña, Distribución funcional del ingreso en Argentina. Ayer y hoy, Documentos de trabajo 4, Buenos Aires, CEPED, FCE-UBA, 2005.

, Concepto, medición y utilidad de la distribución funcional del ingreso, Argentina 1993-2005, Jornadas de Economía, Uni- versidad de General Sarmiento Malvinas Argentinas, 2006.

Lindenboim, Javier, Reflexiones sobre la evolución industrial argentina y el uso de datos censales compatibles, Cuadernos del CEUR NúM. 9, Buenos Aires, CEUR, 1984.

,"El mercado de trabajo en la Argentina en la transición secular: cada vez menos y peores empleos" en Lindenboim, Javier y Claudia Danani (coordinadores), Entre el trabajo y la política. Las reformas de las políticas sociales argentinas en perspectiva comparada, Buenos Aires, Editorial Biblos, 2003

"La fuerza de trabajo en el siglo XX. Viejas y nuevas discusiones", en Torrado, Susana (compiladora), Población y bienestar en la Argentina. Del primero al segundo centenario, Buenos Aires, EDHASA, 2007.

" "Reestructuración industrial y empleo. Mitos y realidades", en Desarrollo Económico, vol. 32, núm. 126, Buenos Aires, IDES, 1992.

, El reparto de la torta, Colección Claves para Todos (dirigida por José Nun), Buenos Aires, 2005.

Llach Juan José y Carlos Sánchez, Los determinantes del salario en la Argentina. Un diagnóstico de largo plazo y propuestas de políticas, Estudios núm. 29, año VII, Córdoba, IRREAL, enero-marzo, 1984.

Marshall, Adriana, El mercado de trabajo en el capitalismo periférico: el caso de Argentina, Cuadernos del Pispal, México, El Colegio de México, 1981.

Maurizio, Roxana, "Macroeconomic regime, trade openness, unemployment and inequality. The Argentine Experience", en Policy Perspective on Growth, Economic Structure and Poverty Reduction' Conference, Beijing, IDEAS, 2007.

Ministerio de Economía y Obras y Servicios Públicos, Sistema de cuentas nacionales. Argentina. Año base 1993, Buenos Aires, 1999.

Monza, Alfredo, "La evolución de la informalidad en el área metropolitana en los años noventa. Resultados e interrogantes", en Carpio, J., E. Klein, E. e I. Novacovsky (comp.), Informalidades y exclusión social, Buenos Aires, FCE/SIEMPRO/OIT, 2000. 
Muller, Alberto Eugenio Guido, Desmantelamiento del Estado de Bienestar en la Argentina, Cuadernos del CEPED, núm. 6, Buenos Aires, FCE-UBA, 2002.

Rapoport, Mario, Historia económica, política y social de la Argentina: 1880-2003, Buenos Aires, Ariel, 2006.
Secretaría de Asuntos Económicos, Producto e ingreso de la República Argentina en el periodo 1935-1954, Buenos Aires, 1955.

Torrado, Susana, Estructura social de la Argentina: 1945-1983, Buenos Aires, Ediciones de la Flor, 2002.

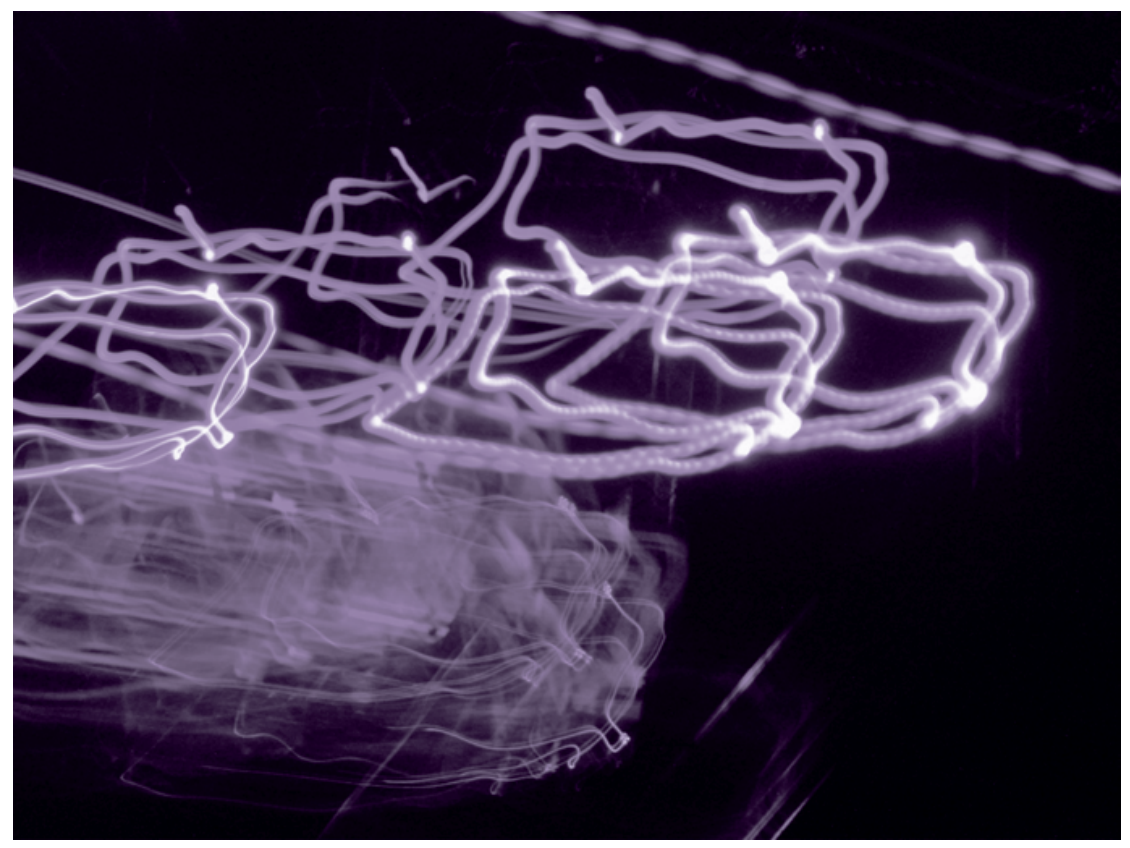

A modo de ola 1, Buenos Aires, 2005. PAI 